IZA DP No. 7702

Money on the Table? Firms' and Workers' Gains from Productivity Spillovers through Worker Mobility

Andrey Stoyanov

Nikolay Zubanov

October 2013 


\title{
Money on the Table? Firms' and Workers' Gains from Productivity Spillovers through Worker Mobility
}

\author{
Andrey Stoyanov \\ York University \\ Nikolay Zubanov \\ Erasmus University Rotterdam \\ and IZA
}

\section{Discussion Paper No. 7702 \\ October 2013}

\author{
IZA \\ P.O. Box 7240 \\ 53072 Bonn \\ Germany \\ Phone: +49-228-3894-0 \\ Fax: +49-228-3894-180 \\ E-mail: iza@iza.org
}

\begin{abstract}
Any opinions expressed here are those of the author(s) and not those of IZA. Research published in this series may include views on policy, but the institute itself takes no institutional policy positions. The IZA research network is committed to the IZA Guiding Principles of Research Integrity.

The Institute for the Study of Labor (IZA) in Bonn is a local and virtual international research center and a place of communication between science, politics and business. IZA is an independent nonprofit organization supported by Deutsche Post Foundation. The center is associated with the University of Bonn and offers a stimulating research environment through its international network, workshops and conferences, data service, project support, research visits and doctoral program. IZA engages in (i) original and internationally competitive research in all fields of labor economics, (ii) development of policy concepts, and (iii) dissemination of research results and concepts to the interested public.
\end{abstract}

IZA Discussion Papers often represent preliminary work and are circulated to encourage discussion. Citation of such a paper should account for its provisional character. A revised version may be available directly from the author. 


\section{ABSTRACT}

\section{Money on the Table? Firms' and Workers' Gains from Productivity Spillovers through Worker Mobility}

We estimate how much of the gains from productivity spillovers through worker mobility is retained by the hiring firms, by the workers who bring spillovers, and by the other workers. Using linked employer-employee data from Danish manufacturing for the period 1995-2007, we find that at least two-thirds of the total output gain of $0.11 \%$ per year is netted by the firms, while the workers who bring spillovers receive at most $6 \%$ of it as the wage premium. The large share retained by the firms implies that spillovers through worker mobility are mostly a positive externality to them.

\section{NON-TECHNICAL SUMMARY}

Firms benefit from outside knowledge, which they can access, among other channels, through hiring new workers. The mounting empirical evidence suggests that firms' productivity gains traceable to hiring new workers account for a nontrivial share of the aggregate productivity growth. Is any part of those gains redistributed from the firms to the workers in the form of a higher salary?

To answer this question, we track the movements of workers between firms in the Danish manufacturing sector. We find that new workers coming from more productive firms increase the hiring firms' productivity, the more the larger the productivity gap between the sending and receiving firms is. (Hiring workers from less productive firms is neutral to productivity.) The workers, new as well as incumbent, benefit too. However, the workers' total wage gains make up only about a third of the firms' productivity gains from worker mobility.

Why is this finding interesting? One would think that the net gains from worker mobility to hiring firms (i.e., productivity gains minus wage gains) would be brought to virtually zero by firms' trying to outbid each other on a competitive labor market. Our findings are in stark contrast with this prediction. The possible reasons behind the moving workers' not receiving the full gains from mobility - lack of competition between firms, limited observability of workers' potential and other "information asymmetries" - need further research. Whatever the reason, the market for knowledge embedded in the workers does not seem to be fully efficient.

JEL Classification: D24, J31, J60

Keywords: productivity spillovers, worker mobility, wages, matched employer-employee data

Corresponding author:

Nikolay Zubanov

Erasmus University Rotterdam

Erasmus School of Economics

Burg. Oudlaan 50

3062 PA Rotterdam

The Netherlands

E-mail: zubanov@ese.eur.nl

\footnotetext{
* The authors acknowledge the Labor Market Dynamics Group (LMDG) at Aarhus University Department of Economics and Business for support and making the data available. LMDG is a Dale T. Mortensen Visiting Niels Bohr professorship project sponsored by the Danish National Research Foundation.
} 


\section{Introduction}

The importance of knowledge spillovers across firms as a factor affecting economic performance has motivated a literature on the mechanisms facilitating these spillovers. One mechanism proposed in the theory part of this literature (Fosfuri et al., 2001; Markussen, 2001; Glass and Saggi, 2002; Dasgupta, 2012) operates through interfirm worker mobility, whereby newly hired workers carry knowledge between their previous and new firms. Several recent empirical studies, including Gorg and Strobl (2005), Markusen and Trofimenko (2009), Balsvik (2011), Parrotta and Pozzoli (2012) and Stoyanov and Zubanov (2012), have documented the workings of this mechanism, linking firm productivity gains to talent inflows from outside. ${ }^{1}$ A related but less well-studied question is - how much of these gains is given back to the workers as a wage premium? Or, put differently, to what extent are they an externality to the hiring firms, uncompensated by the price eventually paid to the bearers of knowledge on a competitive labor market? Our study tries to answer this important question.

The existing literature on the wage effects of spillovers through worker mobility finds that part of the ensuing output gains is indeed remitted to the workers - at least in the case of workers moving from foreign- to domestic-owned firms, which is the focus of this literature. It finds in particular that domestic firms pay a wage premium to new hires with foreignfirm experience over the wages of otherwise similar workers without such experience. This premium is substantial, estimated at $3.4 \%$ by Pesola (2011) for workers with a university degree, and at 1 to $5 \%$ (depending on tenure) by Balsvik (2011). The other workers benefit as well, seeing their wages grow in step with the share of ex-foreign firm employees in their firms (Poole, 2013). Hiring foreign specialists by domestic firms is also linked to wage increases in those firms, estimated at 4.5-6.2\% depending on skill level (Markussen and Trofimenko,

\footnotetext{
${ }^{1} \mathrm{~A}$ related literature on patent citations, historically the first to talk about knowledge spillovers, found a link between the movements of $\mathrm{R} \& \mathrm{D}$ workers and citations by their new employers of the patents granted to their previous employers (Almeida and Kogut, 1999; Song, Almeida and Wu, 2003; Oettel and Agrawal, 2008; Singh and Agrawal, 2011).
} 
2009).

The above literature leaves a significant room for contributions, which we make in several directions, all related to our research question. First, we estimate both output and wage gains from worker mobility within a unified empirical framework. Most of the existing literature looks only at the wage gains, which information, though essential, is not enough to calculate the distribution of the output gains between firms and workers. Even when gains to both parties are estimated, as in Markussen and Trofimenko (2009) and Balsvik (2011), they are calculated for either moving or incumbent workers, but not for both. Second, we calculate spillovers from worker mobility between any pair of firms regardless of their domicile. Thus, our work goes beyond the confines of the existing literature focussing on worker movements from foreign to domestic firms, which make up only a small part of the total labor turnover even in very open economies. Doing so requires a measure of a receiving firm's exposure to spillovers through worker mobility other than foreign vs. domestic ownership of the sending firm. The lack of such measure in the existing literature forces the researcher to narrow down the study scope, to assume that all foreign-owned firms are equally good sources of knowledge spillovers, and to ignore domestic firms as a source of potentially useful knowledge. An empirical method that we have developed to help relax these limitations is another contribution of our study.

To outline our method, we identify the workers bringing spillovers, whom we call spillover potentials (SPs), as those hired from firms more productive than their current employer. This definition is consistent with the theories behind spillovers through worker mobility (for example, Dasgupta, 2012) that treat the exposure to superior knowledge, which is manifested in higher productivity, as the source of spillovers. Our measure of a firm's exposure to spillovers through worker mobility is based on what we call the productivity gap - the difference between the log total factor productivities (TFP) of a moving worker's sending and receiving firms. To apply this measure at the firm level, we average the gap across all the SPs in each firm and year and multiply the resulting average by SPs' share in the firm's workforce. We 
also use the gap in the individual wage equation, when calculating SPs' wage premium as part of our analysis.

Underlying our definitions of the SPs and the gap is the TFP, which we calculate from a Cobb-Douglas production function. Having identified SPs and constructed the gap at the firm level, we reestimate the original production function equation with the gap included, whereby we obtain the coefficient on the gap which measures the output gains linked to hiring SPs. This two-stage procedure entails a number of estimation issues, which we address. We calculate SPs' wage premium over otherwise similar non-SPs as the coefficient on the gap in the individual wage equation with controls including firm-year fixed effects. The non-SPs' wage gain is then given by the coefficient on the gap in the firm-level wage equation with the previously estimated firm-year fixed effect as the dependent variable. Having expressed the total output and SP and non-SP wage gains as functions of the gap, we compute these gains for the representative firm, SP and non-SP, using the appropriate sample averages. Finally, we calculate the shares of the gains to each party in the total.

We apply our empirical framework to the linked worker-firm data from the Danish manufacturing sector collected over the years 1995-2007. Our findings are robust to various model specifications and are not confined to any particular worker type, industry group or time period. To preview the results from our preferred specification, the estimated total output gain linked to SPs is $0.11 \%$ in the year after hiring, or just under a tenth of the annual productivity growth averaged over the sample period. Compared to otherwise similar non-SPs, SPs receive a wage premium of $0.79 \%$ per year on average. Non-SPs benefit too, though their average wage gain is a lot less, $0.08 \%$ per year. With SPs making up only $2.14 \%$ of all the workers, the total wage gain from spillovers through mobility is $0.09 \%$ per year. Expressing the wage gains in output terms and subtracting the total wage gain from the total output gain, we calculate that firms net at least two-thirds, and non-SPs at least 15\%, of the total output gain, whereas SPs retain at most 6\%. Since firms receive most of the output gains from SPs, we conclude that spillovers through worker mobility are largely a positive 
externality to the hiring firms.

The remainder of the paper develops the themes of this introduction. Section 2 estimates the productivity and total output gains linked to SPs, presenting the definitions and empirical framework (sections 2.1, 2.2, 2.3), the data (section 2.4), and the baseline results (section 2.5). Wage gains to SPs and non-SPs are estimated in Section 3, which includes a description of econometric estimation issues (section 3.1) and results (section 3.2). The remaining section 3.3 presents a framework for calculating the output gains distribution and reports the results. Section 4 presents three extensions of our main analysis: productivity and wage gains from worker mobility within and between industries (Section 4.1), the same by moving workers' skill level (Section 4.2), and the evolution of these gains in time (Section 4.3). Section 5 concludes.

\section{Productivity gains from worker mobility to firms}

In this section, we estimate the productivity gains to firms from hiring spillover potentials (SPs) as compared to hiring none. Our estimation procedure, detailed below, combines elements of the approaches featured in Balsvik (2011) and Stoyanov and Zubanov (2012) with an additional econometric instrumentarium to obtain more accurate and detailed estimates from the data. The approach to estimating productivity gains from SPs proposed in Stoyanov and Zubanov (2012) was to regress their receiving firms' per-worker value added on the productivity gap defined as the lagged sending-receiving firm difference in per-worker value added averaged across the SPs and multiplied by their share in the receiving firm's workforce. The gap measure is an attractive feature of this approach because it allows productivity gains from SPs to differ depending on their sending and receiving firms; we will therefore use the intuition behind this measure in the present study.

Yet, there are reasons to argue that the productivity gap should be measured and applied within the production function context. First, doing so takes into account differences in capital and other non-transferable inputs between sending and receiving firms, which would 
otherwise enter the productivity gap without resulting in any spillovers. Second, the output gains from SPs, which is one of the interests of our study, can be calculated more directly and conveniently from the production function estimates than from the effect of SPs on per-worker value added only. Lastly, the currently available production function estimators, such as Olley and Pakes (1996) and its extension in Wooldridge (2009), are robust to some (albeit not all) econometric problems that will have a bearing on the estimates of our direct interest but cannot be addressed within the simpler, production function-free framework. We therefore adopt Balsvik's (2011) approach to estimating the gains from SPs based on the production function in which SPs and the rest of the workers are included as components of the total labor input. We extend her approach by allowing the gains from SPs to vary depending on the magnitude of the productivity gap. Modeling spillovers through worker mobility within the production function context and as a function of sending and receiving

firm characteristics will lay the foundations for a rich and generally applicable regression specification. Doing so will bring discipline to it, clarifying the identifying assumptions behind the estimates it produces and threats to their consistency, and suggesting ways of dealing with these threats.

\subsection{Definitions and the regression specification}

We model firm $i$ 's output in year $t, Y_{i t}$, as a Cobb-Douglas function of labor $(L)$, capital $(K)$ and material $(M)$ inputs and $\operatorname{TFP}(A)$ :

$$
Y_{i t}=A_{i t} K_{i t}^{\beta_{k}} L_{i t}^{\beta_{l}} M_{i t}^{\beta_{m}}
$$

Assuming that the gains from SPs come solely in the form of higher labor productivity, we capture the productivity difference between SPs and the rest of the workers by specifying 
labor input in efficiency units:

$$
\begin{aligned}
L_{i t} & =L_{i t}^{R}+\delta_{i t} \cdot L_{i t}^{S P} \\
& =\left(L_{i t}^{R}+L_{i t}^{S P}\right)\left(1-s_{i t}+s_{i t} \cdot \delta_{i t}\right) \\
& =\widetilde{L}_{i t}\left(1+s_{i t} \cdot\left(\delta_{i t}-1\right)\right),
\end{aligned}
$$

where $\widetilde{L}=L^{S P}+L^{R}$ is the total labor input in nominal units ${ }^{2}$ (the sum of headcounts of SPs and the rest of the workers), $s$ is SPs' share in total workforce, and $\delta \geq 1$ is the measure of labor productivity advantage (LPA) of spillover potentials over the rest of the workers, which we specify later in this section. ${ }^{3}$ Putting the expression for labor input in equation (1) back into the production function gives

$$
Y_{i t}=A_{i t} K_{i t}^{\beta_{k}} M_{i t}^{\beta_{m}} \widetilde{L}_{i t}^{\beta_{l}}\left[1+s_{i t} \cdot\left(\delta_{i t}-1\right)\right]^{\beta_{l}}
$$

From equation (2), hiring $\operatorname{SPs}(s>0$ and $\delta>1)$ compared to hiring none $(s=0$ or $\delta=1)$ increases firm productivity by a factor of $\left[1+s_{i t} \cdot\left(\delta_{i t}-1\right)\right]^{\beta_{l}}$. This gain comes from SPs increasing the overall labor productivity by a factor of $1+s_{i t} \cdot\left(\delta_{i t}-1\right)$.

Estimating equation (2) and hence calculating the productivity gains from SPs requires, as a minimum, identifying SPs in order to measure their share, $s_{i t}$. As in Stoyanov and Zubanov (2012), we identify them in each firm $i$ and year $t$ as the workers hired in year $t-1$ from firms with a higher TFP than $i$ in year $t-2$, the last full year when those workers were in their previous firms and had access to knowledge there. We exclude those hired in year $t$, because, not knowing the exact date of their joining the firm, we cannot be sure that they have spent enough time in their new firm to affect its productivity by applying knowledge from their previous firms. Indeed, no productivity gains traceable to SPs were detected in

\footnotetext{
${ }^{2}$ Depending on whether SPs are observable to the firm or not, the firm's choice variable can be either the numbers of SPs and other workers separately, or the total labor input. Our methodology can handle both cases.

${ }^{3}$ Although, for simplicity of exposition, in equation (1) we abstract from other factors affecting efficiency units of labor, such as human capital, we do control for many such factors in our empirical analysis.
} 
the year of their hiring. We will also explore the spillover potential of the workers hired before year $t-1$, who might still reveal some knowledge from their previous firms, as an extension to our baseline empirical model in section 4.3 .

While SPs' LPA $\delta$ could be estimated as an additional parameter of the production function, as in Balsvik (2011), our data permit a richer characterization of LPA: not as a constant parameter but rather as a function of actually observed worker movements between firms. Our characterization of $\delta$ is based on Stoyanov and Zubanov's (2012) measure of the productivity gap, which was motivated by the following two insights from empirical literature. First, to the extent that the knowledge from their previous firms makes SPs more productive, their LPA will be proportionate to the technological distance between their sending and receiving firms. Assuming that better technology translates into higher productivity, $\delta$ should be proportionate to the TFP difference between SPs' new and previous firms. Second, given the technological distance between the sending and receiving firms, $\delta$ should be proportionate to the degree of knowledge transferability from sending to receiving firms, which depends, in particular, on the commonality of technology used by the two firms. The following specification for $\delta$ combines both these insights:

$$
\delta_{i t}=\left(\prod_{j=1}^{N_{i t}^{S}} \frac{A_{j, i, t-2}^{S}}{A_{i, t-2}}\right)^{\frac{\eta}{N_{i t}^{S}}}
$$

where $N_{i t}^{S}$ is the number of spillover potentials employed in firm $i$ according to our definition above, $A_{j, i, t-2}^{S}$ is the TFP of worker $j$ 's sending firm in year $t-2$, and $0 \leq \eta<1$ is a parameter measuring the degree of knowledge transferability. It is easy to see that, given our definition of spillover potentials, $\delta$ is guaranteed to be at or above 1, as postulated in equation (1), since $A_{j, i, t-2}^{S} / A_{i, t-2} \geq 1$, and that $\delta$ increases in magnitude with the productivity difference between sending and receiving firms and with the knowledge transferability parameter $\eta$.

Incorporating the expression for $\delta$ above in the original production function (2), we obtain 
an estimable regression equation from which productivity gains from SPs can be calculated. Taking logarithms of both parts of $(2)$ and noting that $\ln \left[1+s_{i t} \cdot\left(\delta_{i t}-1\right)\right] \approx s_{i t} \cdot\left(\delta_{i t}-1\right)$ for $s_{i t} \cdot\left(\delta_{i t}-1\right)$ close to 0 , gives

$$
y_{i t}=a_{i t}+\beta_{k} k_{i t}+\beta_{l} l_{i t}+\beta_{m} m_{i t}+\beta_{l}\left(\delta_{i t}-1\right) s_{i t},
$$

where $y, a, k, l, m$ are the logarithms of output, TFP and the factor inputs in nominal units (that is, in headcount for labor input). Further noting that $(\delta-1) \approx \ln \delta$ for $\delta$ close to 1 and applying the expression for $\delta$ in (3), we arrive at the baseline equation linking the firm's output and its exposure to spillovers:

$$
y_{i t}=a_{i t}+\beta_{k} k_{i t}+\beta_{l} l_{i t}+\beta_{m} m_{i t}+\beta_{l} \cdot \eta \cdot g a p_{i t} \cdot s_{i t}
$$

where the term

$$
\operatorname{gap}_{i t}=\frac{\sum_{j=1}^{N_{i t}^{S}}\left(a_{j, i, t-2}^{S}-a_{i, t-2}\right)}{N_{i, t-1}^{S}}
$$

is the productivity gap reflecting the technological distance between the sending and receiving firms averaged across the SPs in firm $i$. From equation (5), the estimated log productivity gain from hiring SPs vs. hiring none is $\widehat{\beta}_{l} \cdot \hat{\eta} \cdot \widehat{\operatorname{gap}}_{i t} \cdot \hat{s}_{i t}$. This gain increases with the gap, labor intensity of production technology, knowledge transferability between sending and receiving firms, as well as with the share of SPs in the receiving firm's workforce. The latter affects the firm's exposure to knowledge coming with the moving workers: the more of them in the workforce, the higher the exposure and hence, given the gap, the larger the gain. ${ }^{4}$

\footnotetext{
${ }^{4}$ We realize that the assumption that the gains from spillovers are linear in the share of SPs may be restrictive, especially in the presence of learning by other workers. However, we choose to proceed with it for its simplicity and consistency with the specification for labor input in efficiency units in equation (1). Allowing for $s_{i t}$ to enter (5) nonlinearly as a robustness check (available on request) does not change our results.
} 


\subsection{Estimation issues}

We estimate equation (5) in two steps. In the first step, we use a selection of production function estimators, adapted to our case as outlined below, to estimate the production function part of it:

$$
y_{i t}=\beta_{k} k_{i t}+\beta_{l} l_{i t}+\beta_{m} m_{i t}+u_{i t},
$$

from which we recover the TFP,

$$
\hat{u}_{i t}=y_{i t}-\hat{\beta}_{k} k_{i t}-\hat{\beta}_{l} l_{i t}-\hat{\beta}_{m} m_{i t},
$$

the number of spillover potentials in each firm and year (and hence their share, $\hat{s}_{i t}$ ), derived from the condition $\hat{u}_{j, i, t-2}^{S}-\hat{u}_{i, t-2}>0$ for each worker $j$ hired by firm $i$ in year $t-1$, and the gap, ${ }^{5}$

$$
\widehat{\operatorname{gap}}_{i t}=\frac{\sum_{j=1}^{N_{i, t-1}^{S}} \hat{u}_{j, i, t-2}^{S}-\hat{u}_{i, t-2}}{N_{i, t-1}^{S}}
$$

In the second step, we apply the same production function estimators as in the first step to estimate equation (5) with the gap and controls for other factors affecting TFP included (more on controls in the next section 2.3):

$$
\begin{aligned}
y_{i t}= & \beta_{k} k_{i t}+\beta_{l} l_{i t}+\beta_{m} m_{i t}+\theta \widehat{\operatorname{gap}}_{i t} \hat{s}_{i t} \\
& + \text { controls }_{i t}+e_{i t},
\end{aligned}
$$

where $e_{i t}$ is the error term. The knowledge transferability parameter is estimated as $\hat{\eta}=\hat{\theta} / \hat{\beta}_{l}$, its standard error computed with the delta method. Since equation (9) includes variables estimated earlier from equation (6), the standard errors of its coefficients are bootstrapped.

The fundamental problem with estimating a production function at both steps in our procedure is to identify input elasticities in the presence of shocks to TFP observable to the

\footnotetext{
${ }^{5}$ In constructing the gap measure, we will discard the top and bottom $1 \%$ of observations to remove likely outliers.
} 
firms but not to the econometrician. Such shocks will affect the firm's decision on factor inputs, causing a bias in the ordinary least squares (OLS) estimates of their elasticities and hence the TFP and the gap. A second estimation problem, specific to our study, is possible correlation between firms' hiring decisions (and hence the gap) and their observed TFP shocks. This problem will cause an upward bias to the gap's coefficient, as firms with a higher observed TFP shock will want, and can better afford, to hire workers from more productive firms. Several estimators proposed in the literature can address both estimation problems, of which we apply two - Olley and Pakes (1996) and its extension in Wooldridge (2009) - with an adaptation to suit our particular estimation problem as we now outline.

Denote $\omega_{i t}$ the component in the production function equation's error term $\left(u_{i t}\right.$ in the first-step and $e_{i t}$ in the second-step equation) that is observed by the firm and thus affects the firm's factor input choice. The basic version of Olley and Pakes (1996) two-stage estimator, henceforth OP, derives labor and materials elasticities at the first stage with $\omega_{i t}$ proxied by a control function specified nonparametrically as a polynomial in capital and investments. At the second stage, it derives capital input elasticity (which could not be estimated at the first stage because of collinearity of capital input with the control function) from the first-stage residuals. To identify capital input elasticity at the second stage, OP use the assumption that $\omega_{i t}$ follows a first-order Markov process to express it as a polynomial of lagged capital and investments plus a random error. ${ }^{6}$

Wooldridge (2009) proposes a more efficient estimator, which combines the two steps in $\mathrm{OP}$ in one, proxying $\omega_{i t}$ directly with the polynomial in lagged capital and investments. In addition to efficiency, another advantage of this estimator, henceforth WOP, is that it can use the GMM estimation framework to relax the assumption, implicit in OP, that labor and material inputs are freely chosen at each $t$ upon realization of $\omega_{i t}$, by instrumenting these

\footnotetext{
${ }^{6}$ One could ask whether the gap's coefficient $\theta$ will be identifiable when the gap's effect is perfectly observed by the firm, in which case the term $\theta \widehat{g a p}_{i t} \hat{s}_{i t}$ in equation (9) will belong to the observed error term $\omega_{i t}$ and will be fully absorbed by the control function in the first stage. $\theta$ will be identified in the second stage, along with capital input elasticity $\beta_{k}$, as long as $\theta \widehat{g a p}_{i t} \hat{s}_{i t}$ is non-dynamic, which, given the low autocorrelation in it, seems to be the case in our data.
} 
inputs with their lags. The extra flexibility of WOP in allowing dynamic factor input choice makes it our preferred production function estimator.

Our implementation of the OP and WOP estimators differs from their canonical versions in that we allow for a second-order Markov process in $\omega_{i t}$, which involves respecifying the control function so as to identify not only $\omega_{i t}$ but also $\omega_{i, t-1}$ as functions of the observables. This adaptation is necessary in the presence of second-order autocorrelation in equation (9)'s error term (true in our data), because the resulting correlation between the error term and the gap through the second lag of TFP entering the gap's formula will bias the gap's coefficient downward. Capturing both lags of $\omega_{i t}$ as functions of observables will remove this bias. As explained in Ackerberg et al. (2007), simultaneous identification of $\omega_{i t}$ and $\omega_{i, t-1}$ requires at least one more proxy variable in addition to investments. Of the broad array of accounting data available to us, we use four such proxies: investment and divestment in buildings and land, and machinery and equipment. The reader is invited to consult the Appendix for more technical details.

\subsection{Controls}

To account for factors affecting TFP other than the gap, we add a number of controls in our second-stage equation (9), including the firm-year averages of worker characteristics (age, gender, experience, education and occupation), calculated separately for the SPs and the rest, firm characteristics (worker separation rates and the shares of workers hired from more and less productive firms in the total), industry-year fixed effects, two lags of TFP, a firm-year average measure of human capital disaggregated by worker type, and the gap constructed for workers from less productive firms. The last three controls merit further explanation. The lags of TFP are included in order to capture autocorrelation in equation (9)'s residuals, which, if present, would bias the coefficient on the gap, because the gap is a function of the second lag of own and sending firms' TFP.

Controlling for possible human capital differences between SPs and the rest of the work- 
ers is important for isolating sources of their LPA other than exposure to knowledge at their previous firms. In addition to including observed worker characteristics, we proxy for unobserved human capital with a measure of it proposed in Abowd, Kramarz and Margolis (1999), which we calculate using the method developed in Abowd, Creecy and Kramarz (2002) and implemented in Cornelissen (2008). Their method relies on worker movements between firms as the source of variance to identify individual- and firm-specific components in the individual wage equation:

$$
w_{j i t}=\lambda+z_{j t} \pi+\xi_{j}+\psi_{i}+v_{j i t}
$$

where $w_{j i t}$ denotes $\log$ wage of worker $j$ employed in firm $i$ in year $t, z_{j t}$ is the vector of worker $j$ 's observable characteristics, $\psi_{i}$ is the firm fixed effect, $\xi_{j}$ is the worker fixed effect, and $v_{j i t}$ is a random error term. Having estimated (10), we calculate for every worker the measure of his or her human capital as the wage net of the firm-specific effect and the error, which we then average at the firm level, producing

$$
\bar{h}_{i t}=\frac{1}{N_{i t}} \sum_{i=1}^{N_{i t}}\left(w_{j i t}-\psi_{i}-v_{j i t}\right)
$$

separately for SPs, movers from less productive firms and stayers. Subtracting the firmspecific component $\psi_{i}$ from the wage renders our measure of human capital free from firmspecific influences (such as compensation policies) which may also be correlated with sending firm's productivity and hence the gap. The measures of human capital in $t$ are constructed from the wages in year $t-2$, the last full year when SPs were in their previous firms.

As an additional control for human capital in the gap's effect, we include the gap measure analogous to (8) but calculated for the workers coming from less productive firms, which we call negative gap. To the extent that the gap's effect is driven by human capital, the coefficients on the positive and negative gaps will be equal, since better quality workers will improve performance by contributing to the receiving firm's human capital stock, just as 
worse quality ones will deteriorate it. On the other hand, if the gap's coefficient reflects spillovers, there will be a positive effect only of the positive gap, formed by the SPs as we have defined them; the knowledge embedded in workers with a negative gap, coming from technologically inferior firms, will just be neutral to the receiving firm's productivity. Thus, the presence of the human capital component in the estimated gap's effect can be gauged by the similarity between the coefficients on the positive and negative gaps.

\subsection{Data}

Our empirical analysis requires information on workers' current and previous employers, necessitating the use of matched employer-employee data. We obtained these data for the years 1995-2007 from Statistics Denmark. The data on workers come from the Integrated Database for Labor Market Research (IDA), covering the total population of individuals aged 15-65 residing in Denmark. Detailed information is available on individual socio-economic characteristics: age, gender, employment status, annual salary and income from other courses, experience, level of education, and skill group. All working individuals are matched to firms where they were employed in the last week of November of each year. The firm data (FIDA) include: industry affiliation, book value of physical capital, sales, workforce size, wages, purchases of materials and energy inputs, as well as detailed data on investments which we use in our estimation procedure to construct the control function. FIDA covers the entire population of firms, of which those with 50 or more workers are surveyed annually, and the rest are surveyed less frequently with the observations in-between interpolated. In our analysis, we use the part of the matched IDA and FIDA data coming from the manufacturing sector.

[Table 1 about here.]

Table 1 lists descriptive statistics measured at the firm and worker level, calculated on the

sample used in our regression analysis. An average firm produces 9.3 million $\left(=e^{9.137} \times 1,000\right)$ Danish Kroner (1.65 million US\$) worth of goods per year, employing 10.5 workers and DKK 1.7 billion and 3.4 million worth of capital and materials. Many firms had had an exposure 
to productivity gains through hiring SPs, which took place in about a third (24.3 thousand) of observations during the sample period. Firms hiring SPs are different from the rest of the sample in that they have larger size (28.8 vs. 10.5 workers), produce more output per worker, employ more skilled workers (75\% mid-skilled or above vs. 63\%), and pay higher wages (192.5 vs. 178.6 thousand DKK per year). Our statistical analysis will control for these differences to determine the part played by spillovers through worker mobility in those firms' superior performance.

Despite some missing data, firms in our sample represent $87 \%$ and $86 \%$ of the manufacturing sector's output and employment, respectively. Therefore, what happens in this sample will be representative of the Danish manufacturing sector as a whole. To be able to project our statistical findings to the sectoral level, we use the concept of representative firm (the last column in Table 1). The representative firm is different from the average firm in that the statistics for the representative firm are averages of the underlying firm-level data weighted by the respective firm's share in total output. Therefore, the representative firm is larger than average on output and factor input measures. Thanks to such weighting, the effects on the representative firm's output, calculated from our regression coefficients, will be the same for the manufacturing sector as a whole.

Turning to workers' data, an average worker is aged 41.6, earning 280.4 thousand DKK per year, and is most likely to be a college-educated male working in a medium-skilled occupation in a large firm (average 210.2 workers). The discrepancies in the averages at the firm and worker levels exist because larger firms, whose weight in total observations at the worker level is greater, produce and pay more. Applying to firm-level observations their weights in total employment levels off these differences; indeed, the worker-level averages are close to those for the representative firms, since firms' weights in total output are close to their weights in total employment. The average worker changes firms once every ten years (more frequently in smaller firms); however, the share of SPs in total observations is only 
about $2 \% .^{7}$ Zooming in on those rare $2 \%$, an average SP is younger (37.4 vs. 41.6), less experienced and less well-paid (257 vs. 280.4 thousand DKK per year) than the rest of the workers. A further analysis will establish whether they are paid a wage premium by their receiving firms compared to otherwise similar workers.

\subsection{Results}

As outlined in section 2.2, we estimate the production function equation (5) in two steps: first, the part of it without the gap (equation (6)), and second, the original equation with the gap and controls added in it (equation (9)). Tables 2 and 3 report the results from the first and second steps, respectively. Before we discuss the estimates of our main interest in this section - the estimated gap and its effect on firm productivity - let us take a brief look at the input elasticities. Their estimates obtained at both steps are nearly identical, so we rely on Table 3 to assist the presentation. The input elasticities are within the range of magnitudes reported in the literature but differ between the three estimators. The labor and capital elasticities decrease as we control for TFP shocks affecting factor inputs in columns (4)-(9), while the materials input elasticity tends to increase. The returns to scale, around 0.95 as estimated by OLS (columns 1-3), decrease to 0.87 in OP (columns 4-6). The application of WOP (columns 7-9) raises the returns to scale to 0.93 due to changes in the coefficients on labor and materials, whose OP estimates may be unstable because of the problems with their identifiability (see Appendix). Although not all differences in the OLS, OP and WOP estimates render themselves to simple explanations, the three estimators produce very similar measures of TFP $(\hat{u})$ with pairwise correlations of $0.94-0.98$, depending on the pair. This similarity implies that our measure of the gap, calculated from $\hat{u}$ according to (8), will not vary much with the production function estimator.

[Table 2 about here.]

\footnotetext{
${ }^{7}$ Another $2 \%$ are workers moving from less to more productive firms. The rest of the job changers are not included in our gap measures because they were either unemployed in the previous year, or come from non-manufacturing sending firms, or just enter the labor market.
} 
Turning to the estimates of our main interest, Table 2 reports descriptive statistics for the gap, the share of SPs, and the product of the two, calculated at the firm and worker level. The averages at the worker level are representative of the entire workforce; therefore, we will use them in illustrating what spillovers through worker mobility mean for the workers (Section 3.2). The firm-level averages are reported in the simple and weighted forms, with weights proportionate to firms' shares in total output, to make them applicable to the representative firm. Since in this section we discuss results for the firms, we will use the weighted firmlevel statistics in Table 2. Looking at these statistics, SPs make up around $2 \%$ of the representative firm's workforce, their gaps averaging at $0.25-0.29$. The small share of SPs in the representative firm will limit the productivity gain that they deliver to it. In fact, the representative firm has the gap times share measure of only $0.0062-0.0070$. In our preferred specification (WOP), the representative firm counts $1.88 \%$ of its workforce as SPs, whose average gap is 0.2725 , and has gap times share of 0.0064 .

[Table 3 about here.]

The main results in Table 3, obtained at the second step of our estimation procedure, are a positive and significant coefficient on the positive gap, and a small and insignificant one on the negative gap. The difference between these coefficients implies that human capital brought in by new workers cannot explain the productivity effect of the gap, since otherwise the two coefficients would be equal. Since the negative gap's effect is small, both statistically and economically, we will focus on the positive gap.

To help further isolate factors other than knowledge spillovers that can operate through the gap, as well as to pinpoint their sources, we run three specifications of the production function equation with different sets of additional controls. The first specification (columns 1, 4, 7) includes the Abowd, Kramarz and Margolis (1999) human capital measure (calculated separately for SPs and others from equation (11)), industry-year fixed effects and two lags of TFP. The second specification (columns 2, 5, 8) includes the same controls plus firm characteristics: separations rate, and shares of new workers hired from more and less pro- 
ductive firms. Finally, the third, and most complete, specification (columns 3, 6, 9) includes the same plus other observable characteristics of the workers, averaged at the firm level: age, gender, experience, education and occupation group within the firm. Comparing the gap's coefficients across these specifications, we see that its effect is mostly influenced by the observed characteristics of the workers, many of which are related to human capital. Yet, most of the gap's effect survives these controls.

Starting with the most complete OLS specification (Table 3's column 3), the gap's coefficient 0.25 implies a receiving firm's productivity gain from hiring SPs equal to 0.25 of its gap times SPs' share in the workforce. For example, a firm hiring $10 \%$ of its workforce from $10 \%$ more productive firms will produce $0.25 \%(=0.25 \times 0.1 \times 0.1)$ more output with the same inputs than a similar firm hiring no SPs. This OLS-based estimate of the productivity gain may be subject to bias due to the gap and labor input being correlated with the receiving firm's TFP shock. Applying the OP and WOP estimators that control for this bias, we observe that, compared to the OLS, the positive gap's coefficient has reduced in magnitude and is now $0.15-0.17$ in the most complete regression specifications (columns 6 and 9). This decrease suggests that firms experiencing a positive TFP shock tend to hire from relatively more productive firms. Still, even controlling for this correlation, the implied productivity gain to a firm hiring $10 \%$ of its workforce from $10 \%$ more productive firms is still a non-negligible $0.171 \%(=0.171 \times 0.1 \times 0.1$, based on the most complete specification estimated with our preferred WOP, column 9).

The productivity gain from SPs to the representative firm is $0.11 \%(=0.171$, the WOP coefficient on the gap, multiplied by 0.0064 , the WOP-based gap times share from Table 2). By virtue of its representativeness of the whole manufacturing sector, we conclude that the sector as a whole grows by the same $0.11 \%$ per year, which is $8.8 \%$ of its annual TFP growth averaged over the sample period. It may thus be conjectured that, if there had been no spillovers through worker mobility in the Danish manufacturing sector, its TFP growth would have been just under a tenth less than actually observed. 
Dividing the WOP gap's coefficient of 0.171 by labor input elasticity, 0.333 , we obtain the knowledge transferability parameter $\hat{\eta}=0.513$. Given our assumption that it is the knowledge gap that underlies the sending-receiving firms' productivity gap, $\hat{\eta}=0.513$ implies that about half of this knowledge is transferable between firms despite technological and other barriers that may hinder this transfer. (More on the role of common technology in spillovers through worker mobility in Section 4.1.)

Calculating $\hat{\eta}$ allows us to estimate SPs' $\log$ LPA as $\hat{\eta} \cdot \widehat{g a p}$. For the representative firm, with the average gap at 0.2725 (Table 2), it is 0.14 , implying that an average SP is $15 \%$ more productive than an average non-SP in that firm. It must be noted that the latter result is based on the assumption that non-SPs do not become more productive by learning from SPs, which process we cannot observe. Allowing for such learning, the log LPA as defined above becomes the upper boundary of the true LPA. Its lower boundary, based on the contrary assumption that every worker learns from SPs and becomes equally productive with them, is 0 . Whatever the productivity differences are between SPs and non-SPs, the overall labour productivity increase traceable to SPs is $\hat{\eta} \cdot \widehat{g a p} \cdot \hat{s}_{i t}$, or $0.33 \%$ for the representative firm. As firms' gains from SPs originate from higher overall labor productivity, a natural question to arise is, whether and how much of these gains are redistributed to the workers in the form of higher wages. We turn to this question in the section that follows.

\section{$3 \quad$ Wage gains linked to spillover potentials}

One can expect to see a wage premium paid to SPs compared to otherwise similar non-SPs because competition works towards aligning factor input payments to their productivity. Thus, Balsvik (2011) found that workers with recent foreign-firm experience hired by domestic firms were paid about 5\% higher wages compared to otherwise similar incumbent workers. Looking at our data, although SPs' average wage is lower than global average (Table 1), controlling for other determinants of wages reveals that they in fact earn more than otherwise similar non-SPs. Figure 1 plots log wages net of observables and worker 
fixed effects estimated from the wage equation (10) (left panel), and the same net of firm fixed effects (right panel), averaged for the workers who changed firms in 2000 (close to the midpoint of our sample's time span) and for those who did not. Figure 1's left panel shows that SPs earn more than other workers do prior to job change, but less than movers from less to more productive firms thereafter. These dynamics, however, are likely to be influenced by moving workers' destinations, since by definition SPs move to less productive firms, which pay relatively low wages, and other moving workers go to more productive, higher-wage firms. Indeed, looking at the wages net of observables, worker and firm fixed effects (Figure 1's right panel), we see that, relative to movers from less to more productive firms, SPs receive a small but persistent wage premium after the move.

[Figure 1 about here.]

There are also signs in the data suggesting that the size of SPs' wage premium depends on the gap. Thus, disaggregating SPs into the first and the fourth quartile of the productivity gap (Figure 2) we observe that workers with the highest spillover potential (4th quartile) receive a substantial wage premium relative to non-SPs, which persists over time. At the same time, the residual wage profile of SPs with the smallest gap (1st quartile) does not differ much from that of movers from less to more productive firms.

[Figure 2 about here.]

The wage premium to SPs may understate the full extent of the redistribution of productivity gains from firms to workers, since non-SPs too can command higher wages after becoming more productive through learning from SPs, evidence of which is reported in Poole (2013). Even if their productivity stays the same, non-SPs may share in their firm's productivity gains through wage bargaining actuated by fairness concerns (Smith, 1995), especially that the differences between SPs and otherwise similar non-SPs are not highly perceptible. Because the wage gains linked to SPs may not be limited to SPs alone, we will also estimate the gains to other workers. Bringing all our empirical results together, we complete this section with a calculation of the implied distribution of the total output gains from SPs 
between the firms, the SPs themselves, and the other workers.

\subsection{Estimation issues}

We first estimate the SPs' premium relative to the average wage of otherwise similar workers in their receiving firms, by running the following individual wage equation:

$$
\begin{aligned}
\ln w_{j i t}= & \gamma \cdot \widehat{\operatorname{gap}}_{j i t}+\gamma^{-} \cdot \widehat{\operatorname{gap}}_{j i t}^{-}+\phi_{i t} \\
& + \text { controls }_{j i t}+v_{j i t},
\end{aligned}
$$

where $\ln w_{j i t}$ is log wage of worker $j$ (not necessarily an SP) in firm $i$ in year $t$ (one year after

the job move, if any), $v_{j i t}$ is the random error term, $\widehat{g a p}_{j i t}$ is the productivity gap, calculated for each SP separately as the TFP difference between their sending and receiving firms in year $t-2$, and $\widehat{\operatorname{gap}}_{j i t}^{-}$is the negative gap as defined in section 2.3, also calculated at the individual level. Hence, $\widehat{\operatorname{gap}}_{j i t}=0$ for a worker coming from a less productive firm, $\widehat{\operatorname{gap}}_{\text {jit }}^{-}=0$ for an $\mathrm{SP}$, and $\widehat{\operatorname{gap}}_{\text {jit }}^{-}=\widehat{\operatorname{gap}}_{\text {jit }}=0$ for a job stayer. The controls include worker characteristics (firm characteristics are subsumed by the firm-year fixed effects, $\left.\phi_{i t}\right)$ : age, gender, education, skill group, experience, two dummy variables indicating whether a worker comes from a more or a less productive firm, the measure of human capital estimated from equation (10) separately for SPs, other movers and stayers, and dummy variables corresponding to the number of job transitions during the sample period. The firm-year fixed effect $\phi_{i t}$ measures the mean $\log$ wage in the respective firm and year after controlling for individual worker characteristics. Because these characteristics include the gap, $\phi_{i t}$ can be interpreted as the mean log wage of non-SPs (for whom $\widehat{g a p}=0$ ). Hence, coefficient $\gamma$ measures the wage premium to SPs relative to otherwise similar non-SPs as the fraction of the gap.

We proceed to calculating the effect of SPs on the wages of otherwise similar non-SPs by running a firm-level wage regression with the estimated firm-year fixed effects $\hat{\phi}_{i t}$ as the 
dependent variable:

$$
\begin{aligned}
\hat{\phi}_{i t}= & \Gamma \widehat{\operatorname{gap}}_{i t} \hat{s}_{i t}+\Gamma^{-} \widehat{\operatorname{gap}}_{i t}^{-} \hat{s}_{i t}^{-}+\Phi_{i}+\tau_{k t} \\
& +\operatorname{controls}_{i t}+V_{i t},
\end{aligned}
$$

where $\widehat{\operatorname{gap}}_{i t}^{-} \hat{s}_{i t}^{-}$is the negative gap times the share of moving workers from less productive firms, $\Phi_{i}$ and $\tau_{k t}$ are firm and industry-year fixed effects, controls include firm and worker average characteristics (the same as in the individual wage equation (12)) and two lags of TFP $(\hat{u})$ estimated from the production function equation (6), and $V_{i t}$ is the random error term. Coefficient $\Gamma$ measures the average wage gain to non-SPs' as the fraction of the gap times the share of SPs in a given firm and year. Because we wish to use estimates from the firm-level equation (13) to make inferences with respect to the average worker in our sample, we will estimate (13) using weighted OLS with weights proportionate to the firms' shares in total employment.

Combining the estimates from individual- and firm-level wage equations (12) and (13), we derive the wage gains to $\operatorname{SPs}\left(\Delta w^{S P}\right)$ and non-SPs $\left(\Delta w^{n S P}\right)$ as

$$
\begin{aligned}
\Delta w_{i t}^{n S P} & =\hat{\Gamma} \cdot \widehat{\operatorname{gap}}_{i t} \hat{s}_{i t} \\
\Delta w_{j i t}^{S P} & =\hat{\Gamma} \cdot \widehat{\operatorname{gap}}_{i t} \hat{s}_{i t}+\hat{\gamma} \cdot \widehat{\operatorname{gap}}_{j i t},
\end{aligned}
$$

and the average wage gain as

$$
\begin{aligned}
\Delta \bar{w}_{i t} & =\hat{s}_{i t} \cdot \frac{1}{N_{i, t-1}^{S}} \cdot \sum_{j=1}^{N_{i, t-1}^{S}} \Delta w_{j i t}^{S P}+\left(1-\hat{s}_{i t}\right) \cdot \Delta w_{i t}^{n S P} \\
& =(\hat{\gamma}+\hat{\Gamma}) \cdot \widehat{\operatorname{gap}}_{i t} \hat{s}_{i t}
\end{aligned}
$$

Because the above expressions for the wage gains involve the gap and the share of SPs in 
the firm, which vary by firm and year, it is convenient to calculate them for the average worker whose data are reported in the "Workers" part of Table 2. Thanks to the average worker's representativeness, this calculation will also apply to the manufacturing sector's labor force as a whole, enabling us to compare the gains to the workers with the gains to the firms estimated in Section 2.5. Drawing on our preferred production function estimator (WOP), the average worker is employed in the firm where $\hat{s}_{i t}=2.14 \%$ of employees are

SPs whose average gap is $\left(N_{i, t-1}^{S}\right)^{-1} \sum_{j=1}^{N_{i, t-1}^{S}} \widehat{\operatorname{gap}}_{j i t}=0.2456$, resulting in the gap times share $\widehat{g a p}_{i t} \hat{s}_{i t}=0.0053$. These statistics are different from their equivalents for the representative firm because firms' shares in total output, though close, are not equal to their shares in total employment.

\subsection{Results}

Table 4 presents estimation results for the individual wage equation (12) run with the gap values estimated previously with OLS, OP and WOP estimators. Consistent with our earlier results, the negative gap's coefficient, $\gamma^{-}$, is small and insignificant, implying no significant wage premium (or penalty) to the new workers who are not SPs. The positive and significant coefficient on the gap, $\gamma$, implies that there is indeed a wage premium to SPs proportionate to the knowledge they bring as measured by their productivity gap. Comparing the estimates in specifications with and without controls, we conclude that a large part of this wage premium can be explained by the characteristics of the workers who receive it, as the coefficient on the positive gap goes down in magnitude as we add worker controls. In the end, with all controls included in our preferred specification (column 6), the wage premium to SPs on top of the average wage in a given firm and year is 0.032 of their gap. Hence, the average $\mathrm{SP}$, whose gap is 0.2456 , earns an extra $0.79 \%$ per year on top of the average non-SP wage in his or her firm. Relative to the sample average real wage growth, $4 \%$ per year, this premium is not insignificant. However, because SPs make up only $2.14 \%$ of the workforce, their wage premium makes little difference to the total wage bill, increasing it by a mere 
0.017\% compared to the hypothetical case of no worker mobility across firms.

[Table 4 about here.]

The estimates from equation (13) are presented in Table 5. Unlike that on the negative gap, the coefficient on the gap, $\Gamma$, is consistently positive and significant across the estimators and specifications, even though worker and firm characteristics explain a large part of the effect it measures. The gap's coefficient in our most preferred and complete specification (column 9), $\Gamma=0.146$, implies that non-SPs in a firm hiring $10 \%$ of its workforce from $10 \%$ more productive firms gain, on average, $0.15 \%(=0.146 \times 0.1 \times 0.1)$ in wages per person per year compared to the counterfactual of hiring the same $10 \%$ but non-SPs. For the average non-SP in our sample this wage gain stands at $0.08 \%(=0.146 \times 0.0053$, average gap times share) per year. Adding this average wage gain to SPs' premium calculated above, we obtain their full wage gain: $0.87 \%$ per year, paid in the year following the change of employer. The average wage gain, calculated from equation (15), is $0.09 \%$ per year. Thanks to the representativeness of our sample, this number measures the manufacturing sector's total wage bill increase linked to SPs.

[Table 5 about here.]

Our calculations above point to a considerable redistribution of wage gains from SPs to the rest of the workers. Indeed, if all wage gains were SPs' only, then the average SP would have earned a $4.2 \%$ wage premium per year (= the average wage gain, $0.09 \%$, divided by SPs share in the workforce, $2.14 \%$ ) instead of the actual $0.87 \%$. Comparing this actual wage gain with the possible maximum of $4.2 \%$, as well as the total wage gain of $0.09 \%$ with the total output gain of $0.11 \%$ (section 2.5) suggests that the gains from spillovers through worker mobility are not accrued to SPs alone but are in fact shared between the firms, the SPs and the other workers. We calculate these shares next. 


\subsection{The distribution of the gains from SPs}

Rewrite the total output gain linked to SPs $(\Delta y)$ as the sum of the gain to the firms net of the extra wage costs and the total wage gain $(\Delta \bar{w})$, now expressed as a percentage of output:

$$
\Delta y=(\Delta y-\varphi \Delta \bar{w})+\varphi \Delta \bar{w}
$$

where $\varphi$ is the share of labor costs in total output. (The subscripts are omitted, since we will use sample averages in this section's calculations.) The firms' and workers' shares in the total gain are then, respectively,

$$
\frac{\Delta y-\varphi \Delta \bar{w}}{\Delta y} \text { and } \frac{\varphi \Delta \bar{w}}{\Delta y}
$$

Recalling equations (14) and (15), the SPs' and non-SPs' shares in the total wage gain are, respectively,

$$
\frac{\hat{s} \cdot \Delta w^{S P}}{\Delta \bar{w}} \text { and } \frac{(1-\hat{s}) \cdot \Delta w^{n S P}}{\Delta \bar{w}}
$$

Summarizing, the shares of firms $(F S)$, SPs $\left(W S^{S P}\right)$ and non-SPs $\left(W S^{n S P}\right)$ in the total output gain are

$$
F S=\frac{\Delta y-\varphi \Delta \bar{w}}{\Delta y}, W S^{S P}=\frac{\varphi \hat{s} \cdot \Delta w^{S P}}{\Delta y}, W S^{n S P}=\frac{\varphi(1-\hat{s}) \cdot \Delta w^{n S P}}{\Delta y}
$$

Given the output and wage gains, the share of labor costs in total output $\varphi$ determines the gains distribution between firm and workers: the higher $\varphi$, the lower share in the total gain the firms will net. With no prior information about the value of $\varphi$, we use two alternative measures of it. One is the employment-weighted sample average share of wage costs in total output, 0.223 . This value may be interpreted as the true $\varphi$ 's lower boundary (and hence the firms' gains upper boundary), since it omits statutory contributions paid by the firms as well as implicit costs of employing labor, such as the costs of searching, hiring, training up and 
laying off workers. Our alternative measure is labor input elasticity estimated with WOP, 0.333 (Table 3), which, assuming a Cobb-Douglas production function as we do, would give the share of total labor costs in the profit-maximizing firm's output.

[Table 6 about here.]

Table 6 reports the shares in the total output gain of the firms, the SPs and non-SPs calculated from equations (16). The six sets of shares are based on our two alternative measures of $\varphi$ applied to the the OLS, OP and WOP estimates of the gap, the share of SPs and output gains. The shares calculated with $\varphi=0.223$ (columns 1-3) show that firms net at least three-quarters of the total output gain, and with most of the remaining gains going to other workers, SPs receive about $4 \%$ at best. The firms' share in the total gain goes down as we do the calculations with $\varphi$ equal to the WOP labor input elasticity (0.333), which arguably is a better reflection of the economic costs of employing labor than wages only. However, under $\varphi=0.333$ (columns 4-6), the firms' share in the total output gain is still large, at least two-thirds, while the most generous estimate of the SPs' share is $6 \%$. In fact, the firms retain more than half of the total gains for the values of $\varphi$ up to 0.46 , an improbably high share of labor costs. Our calculations thus suggest that spillovers through worker mobility are largely a positive externality to the firms who net most of the ensuing gains.

The low share of SPs in the total output gain they bring suggests the presence of information asymmetry between SPs and their new employers (and possibly other labor market frictions) preventing their labor productivity advantage being fully converted into a wage premium. To illustrate the importance of information asymmetry in shaping the gains distribution, we redo our calculations in (16) on the results from Balsvik (2011), whose data and method are comparable to ours, except for one difference - the SPs in her study are the workers with foreign-firm experience hired by domestic firms. Because this experience, unlike the productivity gap, is a highly visible characteristic, their spillover potential should be better recognized and rewarded. Indeed, their $5 \%$ wage premium over otherwise similar 
workers and the associated output gain of $0.27 \%$ imply that SPs retain $18.8 \%$ of that gain, ${ }^{8}$ which is higher than our estimated 4-6\%. Hence, information asymmetry between SPs and their new employers, which is larger in our general case than in a particular case of workers with foreign-firm experience, can plausibly explain why our SPs' wage premium is relatively low.

\section{Extensions}

\subsection{Productivity and wage gains from worker mobility within and between industries}

As the movement of workers is not confined by a particular industry, SPs with the same productivity gap may bring varying productivity gains depending on the industry of their origin, since the knowledge they bring may have varying degree of transferability. Our analytical framework can be extended to differentiate between productivity gains through worker mobility within and between industries, by allowing the knowledge transferability parameter $0 \leq \eta<1$ in equation (3) to vary depending on an SP's industry of origin. In this section, we implement this extension by calculating the productivity gaps $\left(\widehat{g a p}_{i t}\right)$ and workers shares $\left(\hat{s}_{i t}\right)$ separately for the SPs hired from within (high $\eta$ ) and outside (low $\eta$ ) each industry group, and by repeating the previous analysis for firms and workers with the newly specified measures. There are nine two-digit industries (NACE classification) in the manufacturing sector, and $55 \%$ of all job changes took place within the same industry.

[Table 7 about here.]

Table 7 lists the regression results for the production function equation (9) and individual and firm average wage equations (12) and (13). The gap's coefficient in column 6 is much larger for spillover potentials moving within the same industry (about 0.35) than for those moving between industries (0.07). The difference between these estimates reveals the impor-

\footnotetext{
${ }^{8}$ The total output gain was calculated as the elasticity of output with respect to SPs' share, 0.1 (Table 8), times their sample average share, $2.7 \%$ in 2000. SPs' share in the total output gain was calculated using the estimated labor input elasticity, 0.376 (Table 8), as $\frac{0.376 \times 0.027 \times 5}{0.27}=18.8 \%$.
} 
tance of knowledge transferability in facilitating spillovers through worker mobility between firms: thanks to common production technology, knowledge is more transferable within than across industries, resulting in higher productivity gains for a given gap. At the same time, the smallness and insignificance of the negative gap's coefficient regardless of the industry implies that knowledge transferability is not part of its effect, or rather lack thereof. As before, the sizable difference between the positive and negative gaps' coefficients implies that human capital cannot explain our results.

Turning to the estimates for the individual wage equation (12) in columns 1-3, we see that, despite the difference in productivity gains brought in by SPs from the same and different industries, their individual wage gains as a share of their gap are nearly the same. The coefficient on the same-industry positive gap in the firm average wage regression $(0.178$, column 9) is not far from its analogue in Table 6 (0.146) estimated for all SPs or the same coefficient for SPs from different industries (0.144). Taken together, the similarity of wage premiums to SPs and dissimilarity of productivity gains to firms does not suggest a strong link between the two, which is perhaps not surprising given how little of the total output gain is given back to the SPs or the workers in general.

\subsection{Productivity and wage gains by worker skill level}

So far in our analysis we have used the measure of a firm's exposure to spillovers through worker mobility, $\eta \cdot \widehat{\operatorname{gap}}_{i t} \cdot \hat{s}_{i t}$, which assumes that, given the share of SPs in the workforce, the productivity gains from spillovers increase with the gap and technology transferability between sending and receiving firms. However, holding these firm-level characteristics fixed, productivity gains brought by SPs, as well as their wages, may still vary depending on the attributes of those workers. One such attribute, on which we focus in this section, is skill group, since SPs in higher-skill groups will have better access to the knowledge of their previous firms than those in lower-skill groups. Using the Statistics Denmark's definitions of skill groups based on the International Standard Classification of Occupations, we classify all 
workers into one of the four skill groups: low-skilled, mid-skilled, high-skilled, and managers. Accordingly, we construct the gaps and corresponding worker shares for each skill group separately and reestimate the production function and wage equations (9), (12) and (13) with these newly defined variables.

[Table 8 about here.]

The results, presented in Table 8, reveal considerable differences in the estimated productivity gains to firms from hiring SPs belonging to different skill groups. Consistent with our expectations, the labor productivity advantage of SPs in higher skill groups (highly-skilled and managers) is much larger than that of the lower skill groups, although even the least skilled SPs still contribute to the hiring firm's productivity. The output gains brought by different skill groups depend not only on their LPA but also on their shares in the workforce. Thus, although manager SPs have the highest LPA (0.292), the total output gains from hiring them $(0.045 \%)$ are in fact lower than those from the mid-skilled $(0.053 \%)$, since managers are scarce.

Turning to the effect on wages by skill group, we observe that SPs' own wage premium (coefficient $\gamma$ ) increases with the skill group, peaking at $6.5 \%$ of their individual gap for managers, or $1.9 \%$ for the representative manager SP. While higher than the average SP's wage premium of $0.79 \%$, it is still only a small fraction of the gap. SPs' contribution to the average non-SP wages in their receiving firms (coefficient $\Gamma$ ) is proportional to their LPA and share in the workforce, with the manager and mid-skill SPs contributing the most. However, the total gains distribution, though varying somewhat in the shares accrued to SPs and non-SPs, features a stably large firms' share across the skill groups. Thus, the positive externality created by the movement of workers from more to less productive firms is not confined to a particular skill group. 


\subsection{The dynamics of spillover potentials' productivity advantage and wage premium}

In this section, we estimate the dynamics of SPs' contribution to their new firms' output and relate it to the developments of their wage premium. Although our analysis so far has been confined to looking at SPs' effects on output and wages the next year, these effects may in fact last longer. For instance, the autoregressive process in TFP will propagate SPs' effect on output, which may be further shaped by the internal dynamics of knowledge implementation. There are also reasons for SPs' wage premium to last several years. First, as we have argued earlier (section 3.3), their premium may be affected by information asymmetry regarding their productivity. Presumably, the information asymmetry should decrease as their tenure progresses, and one should see a closer link between their labor productivity advantage and wage premium. Second, SPs' wage premium may be deferred as their new firms try to ensure that they stay long enough for the output gains they bring to be fully realized. Such deferred pay implies that a wage premium will continue to be paid to SPs in the years after joining, possibly even after their labor productivity advantage is exhausted.

To estimate the dynamics of gap's effect on wages and firm productivity, we rerun the

production function and wage equations (9), (12) and (13) with future output and wages as dependent variables:

$$
\begin{gathered}
y_{i, t+q}=\beta_{k} k_{i, t+q}+\beta_{l} l_{i, t+q}+\beta_{m} m_{i, t+q}+\theta_{q} \widehat{g a p}_{i t} \hat{s}_{i t} \\
+\operatorname{controls}_{i t}+\sum_{p=1}^{q} \vartheta_{p} \widehat{\operatorname{gap}}_{i, t+p} \hat{s}_{i, t+p}, q \geq 1 \\
\ln w_{j, i, t+q}=\gamma_{q} \widehat{\operatorname{gap}}_{j i t}+\gamma_{q}^{-} \widehat{\operatorname{gap}}_{j i t}^{-}+\phi_{i, t+q} \\
+\operatorname{controls}_{j i t}+v_{j, i, t+q},
\end{gathered}
$$




$$
\begin{aligned}
\hat{\phi}_{i, t+q}= & \Gamma_{q} \widehat{\operatorname{gap}}_{i t} s_{i t}+\Gamma_{q}^{-} \widehat{\operatorname{gap}}_{i t}^{-} s_{i t}^{-}+\Phi_{i(q)}+\tau_{k, t+q} \\
& +\operatorname{controls}_{i t}+\sum_{p=1}^{q} \Theta_{p} \widehat{\operatorname{gap}}_{i, t+p} \hat{s}_{i, t+p}+V_{i, t+q},
\end{aligned}
$$

where the notations are the same as in the original equations (9), (12) and (13) presented earlier. An adaptation of the local projections method developed in Jordà (2005) and extended in Teulings and Zubanov (forthcoming), this easy-to-implement estimation procedure is robust to possible dynamic misspecifications in the underlying equations. The coefficients $\gamma_{q}$ and $\Gamma_{q}$ estimate the effects of the gap on SPs' wage premium and non-SPs' wages $q+1$ years after joining the new firm, and the coefficient $\theta_{q}$ measures the effect of the gaps-timesshare on output. The overall wage gain is calculated for each $q$ using equation (15). The inclusion of the gaps times share in the years between $t$ and $t+q$ in (17) and (19) controls for the effects of worker mobility between those dates on the outcome at $t+q$, which might otherwise have been attributed to the gap at $t$. The individual wage equation (18) has not been augmented in a similar way because the gap for a given worker remains the same during the whole tenure at a given firm.

[Table 9 about here.]

Table 9 reports the productivity and wage gains linked to SPs in a five-year period after hiring them. The results show that productivity gains from hiring a given cohort of SPs last several years, reaching a peak in the third year and receding thereafter. The dynamics of wage gains to SPs and non-SPs mimics that of productivity, so that the gains distribution remains fairly stable. The continuing positive effect of SPs results in the five-year total output gain linked to hiring them exceeding the year-after gain of $0.11 \%$ estimated earlier. Thus, calculations based on Table 9's results imply that the total output gain over the fiveyear period after hiring SPs becomes $0.7 \%$ of the baseline output. Over the same period, the average SP and non-SP will gain $4.8 \%$ and $0.5 \%$ of their respective baseline wages, implying the overall wage gain of $0.6 \%$. Calculating the parties' shares in the total output gain over the five-year period using equations (16) with $\varphi=0.333$, we obtain that firms net $70.5 \%$ 
of it, SPs $4.5 \%$, and non-SPs $25 \%$, which is about the same distribution as in the first year after hiring.

The stability of the gains distribution with time, and in particular the steadily low share of SPs in the total gain, does not support our deferred pay hypothesis for SPs. Our results do not seem to be consistent with the gradual reduction of information asymmetry over SPs' value, either. However, the latter possibility cannot be rejected outright, since having to prove themselves again with a new employer undermines SPs' bargaining power over their wages. Exploring the factors affecting the dynamics of spillovers through mobility and their consequences for all parties involved should be a promising direction for further research.

\section{Conclusion}

The central question in our study has been to determine the extent to which productivity spillovers through worker mobility are a pure, uncompensated externality to the receiving firms. To this end, we have estimated the total output gain linked to the movement of workers from more to less productive firms (spillover potentials, or SPs, in our terminology) and their distribution between the firms, the SPs and the rest of the workers. We find that the total output gain from SPs is $0.11 \%$ per year, of which the lion share - at least two-thirds - is retained by the hiring firms, whereas the SPs themselves receive a paltry $6 \%$ at most. This finding implies that worker mobility between more and less productive firms is largely a positive externality for the latter, helping their growth by giving cheap access to superior knowledge developed elsewhere.

We believe ours is the first study to show how output gains from knowledge spillovers through mobility are distributed between all the three parties involved. Another contribution to the relevant literatures is the unified empirical framework we have developed to measure spillovers through mobility, which can be applied to worker movements between any pair of firms regardless of their domicile. One useful feature of our framework, other than its generality, is that it is rich enough to support various extensions of our main research 
question, some of which we have implemented. 


\section{Appendix - Modified Olley and Pakes (1996) and Wooldridge (2009) estimation procedures}

Here we provide a detailed description of the estimation procedures, other than OLS, used for the construction of our TFP and productivity gap measures. Recall the production function equation (6):

$$
y_{i t}=\beta_{l} l_{i t}+\beta_{m} m_{i t}+\beta_{k} k_{i t}+u_{i t}
$$

where residual output $u_{i t}$ consists of two mutually orthogonal components: $\omega_{i t}$, which is observed to the firm at $t$, and $\epsilon_{i t}$, an unobserved productivity shock. The correlation of factor inputs with $\omega_{i t}$ causes bias to their OLS estimates. We discuss two estimators dealing with this bias - the Olley and Pakes (1996), henceforth OP, and the extension of it developed by Wooldridge (2009), which we call WOP estimator. The original versions of both estimators assume a first-order Markov process in $\omega_{i t}$. This assumption is at odds with our specification for SPs' labor productivity advantage (equation (3)), which implies that output in period $t$ may depend on $\omega_{i t-2}$ through the productivity gap term. We adapt these estimators to allow for a second-order Markov process in $\omega_{i t}$, to make them fit into our estimation framework.

\subsection{The OP estimator}

In its original version, the OP estimator proxies $\omega_{i t}$ with observables - capital and investments - linked with it. Assuming the capital stock $(k)$ at $t$ is a deterministic function of itself and investment $(i)$ at $(t-1)$,

$$
k_{i t}=(1-\rho) k_{i, t-1}+i_{i, t-1},
$$

where $0<\rho<1$ accounts for depreciation, the firm will use investment as a tool to build up the optimal capital stock given $\omega_{i t}$. Pakes (1994) showed that the investment function $i_{i t}=$ $f\left(k_{i t}, \omega_{i t}\right)$ that solves the dynamic profit maximization problem given (20) is monotonically increasing in both its arguments, and can thus be inverted for $\omega_{i t}$ : 


$$
\omega_{i t}=g\left(k_{i t}, i_{i t}\right)
$$

Since the functional form of $g(\cdot)$ is unknown, it is approximated with a third degree polynomial in $k_{i t}$ and $i_{i t}$, called the control function.

In the first stage of the OP procedure, labor and materials input elasticities, $\beta_{l}$ and $\beta_{m}$, are estimated from the production function equation with the added control function. Because the control function $g(\cdot)$ is collinear with $\beta_{k} k_{i t}$, capital input elasticity $\beta_{k}$ is estimated in the second stage, where the fitted values

$$
\widehat{\Phi}_{i t}=y_{i t}-\hat{\beta}_{l} l_{i t}-\hat{\beta}_{m} m_{i t}-\hat{\epsilon}_{i t}=\beta_{k} k_{i t}+\omega_{i t}
$$

and the assumption that $\omega_{i t}$ follows a first-order Markov process are used to identify it. The latter assumption allows $\omega_{i t}$ to be expressed as the sum of its conditional expectation as of $(t-1)$ and the error term $\xi_{i t}$ orthogonal to it:

$$
\omega_{i t}=\mathrm{E}\left[\omega_{i t} \mid \omega_{i t-1}\right]+\xi_{i t}=\lambda\left(\omega_{i t-1}\right)+\xi_{i t}=\lambda\left(\widehat{\Phi}_{i, t-1}-\beta_{k} k_{i, t-1}\right)+\xi_{i t}
$$

where $\lambda(\cdot)$ is an unknown function approximated by a third degree polynomial. $\beta_{k}$ is then estimated from the regression

$$
\widehat{\Phi}_{i t}=\beta_{k} k_{i t}+\lambda\left(\widehat{\Phi}_{i, t-1}-\beta_{k} k_{i, t-1}\right)+\xi_{i t}
$$

Our definition of SPs' labor productivity advantage as a function of the sending-receiving TFP gap two years back implies that output in period $t$ may depend on $\omega_{i, t-2}$. A correlation between $\omega_{i t}$ and $\omega_{i, t-2}$ will result in a bias to the estimated gap's coefficient. For example, if $\omega_{i t}$ follows an $\operatorname{AR}(2)$ process with positive autoregression coefficients, which is indeed the case in our data, this bias will be downward. To address this problem, we estimate the 
production function equation with $\omega_{i t}$ following second-order Markov process:

$$
\omega_{i t}=\mathrm{E}\left[\omega_{i t} \mid \omega_{i t-1}, \omega_{i t-2}\right]+\xi_{i t}=\lambda\left(\omega_{i t-1}, \omega_{i t-2}\right)+\xi_{i t}
$$

As explained in Ackerberg et. al. (2007), $\omega_{i t}$ following a second-order Markov process results in the optimum investment choice being a function of both $\omega_{i t}$ and $\omega_{i, t-1}$ :

$$
i_{i t}=f_{1}\left(k_{i t}, \omega_{i t}, \omega_{i t-1}\right)
$$

The problem with this modification of the investment function is that the control function for $\omega_{i t}$ can no longer be constructed in the same way as in the benchmark OP because $\omega_{i t}$ and $\omega_{i, t-1}$ cannot be both identified with capital and investment alone. ${ }^{9}$ There must be at least one variable in addition to investments that firms optimally choose at $t$ for the identification of $\omega_{i t}$ and $\omega_{i, t-1}$ to become possible.

Suppose there is such variable $\left(\right.$ call $b_{i t}$ ) in addition to investment. Then, by analogy with investment, it can be expressed as $b_{i t}=f_{2}\left(k_{i t}, \omega_{i t}, \omega_{i t-1}\right)$, or more compactly,

$$
\left(\begin{array}{l}
i_{i t} \\
b_{i t}
\end{array}\right)=G\left(k_{i t}, \omega_{i t}, \omega_{i t-1}\right)
$$

where $G$ is a function mapping each observation $\left(k_{i t}, \omega_{i t}, \omega_{i t-1}\right)$ into a unique pair $i_{i t}$ and $b_{i t}$. Assuming that $G$ is a bijection of $\left(\omega_{i t}, \omega_{i t-1}\right)$ into $\left(i_{i t}, b_{i t}\right)$, which is a generalization of the monotonicity assumption for the bivariate case, it can be inverted to obtain

$$
\left(\begin{array}{c}
\omega_{i t} \\
\omega_{i t-1}
\end{array}\right)=G^{-1}\left(k_{i t}, i_{i t}, b_{i t}\right)
$$

The first stage of the OP proceeds as usual, with the function $G^{-1}(\cdot)$, approximated as a third-degree polynomial in $k_{i t}, i_{i t}$, and $b_{i t}$, used to control for the productivity shocks

\footnotetext{
${ }^{9}$ Indeed, the control functions for $\omega_{i t}$ and $\omega_{i, t-1}$ in terms of capital and investments will be collinear with each other.
} 
observed to the firm. Consistent estimates of $\beta_{l}$ and $\beta_{m}$, as well as fitted values

$$
\widehat{F}_{i t}=\widehat{\omega_{i t}}+\beta_{k} k_{i t}
$$

are obtained at this this stage the usual way. Substituting the expression for $\omega_{i t}$ from (21), the coefficient on capital is estimated in the second stage from the regression

$$
\widehat{F}_{i t}=\beta_{k} k_{i t}+\lambda\left(\widehat{F}_{t-1}-\beta_{k} k_{i, t-1}, \widehat{F}_{t-2}-\beta_{k} k_{i, t-2}\right)+\xi_{i t},
$$

where the function $\lambda(\cdot, \cdot)$ is approximated by a third-degree polynomial in its two arguments.

We implement the above procedure using four control variables: expenditure on construction and acquisition of buildings and land; purchases of machinery and equipment; total sales of buildings and land; and total disposal of machinery and equipment. While the first two will reflect a firm's response to positive productivity shocks, the latter two will capture the firm's adjustments to negative shocks.

\subsection{The WOP estimator}

Ackerberg, Caves and Frazer (2006) argued that a potential weakness of the OP estimator is identifiability of labor and materials elasticities in the first stage. If labor and materials, like investment, are chosen depending on capital and TFP shock at $t$, these inputs will be collinear with the control function and $\beta_{l}$ and $\beta_{m}$ will not be identifiable. Wooldridge (2009) proposed a GMM framework that enables the OP procedure to complete in one stage by specifying the moment conditions for all factor inputs at once. With $\omega_{i t}$ following a first-order Markov process, and hence expressible as

$$
\omega_{i t}=\lambda\left(\omega_{i t-1}\right)+\xi_{i t}=\lambda\left(k_{i t-1}, i_{i t-1}\right)+\xi_{i t},
$$


the original production function regression can be rewritten as

$$
y_{i t}=\beta_{l} l_{i t}+\beta_{m} m_{i t}+\beta_{k} k_{i t}+\lambda\left(k_{i t-1}, i_{i t-1}\right)+\xi_{i t}+e_{i t}
$$

and estimated using GMM with the moment conditions

$$
\mathrm{E}\left[\xi_{i t}+e_{i t} \mid l_{i t-1}, m_{i t-1}, k_{i t}, k_{i t-1}, i_{i t-1}\right]=0
$$

As with the OP estimator, the unknown function $\lambda(\cdot)$ is approximated with a third degree polynomial in $k_{i t-1}$ and $i_{i t-1}$.

By analogy with the OP estimator, rewriting the production function equation with $\omega_{i t}$ following a second-order Markov process is straightforward:

$$
\begin{aligned}
y_{i t}= & \beta_{l} l_{i t}+\beta_{m} m_{i t}+\beta_{k} k_{i t} \\
& +\lambda\left(k_{i t-1}, i_{i t-1}, b_{i t-1}, k_{i t-2}, i_{i t-2}, b_{i t-2}\right)+\xi_{i t}+e_{i t}
\end{aligned}
$$

With function $\lambda$ approximated with a third-degree polynomial its arguments, equation (22) is estimated with nonlinear GMM with the following moment conditions:

$$
\mathrm{E}\left[\xi_{i t}+e_{i t} \mid l_{i t-1}, m_{i t-1}, k_{i t}, k_{i t-1}, i_{i t-1}, b_{i t-1}, k_{i t-2}, i_{i t-2}, b_{i t-2}\right]=0
$$




\section{References}

Abowd, John M., Francis Kramarz, and David N. Margolis. 1999. "High Wage Workers and High Wage Firms." Econometrica, 67(2): 251-334.

Abowd, John, Robert H. Creecy, and Francis Kramarz. "Computing Person and Firm Effects Using Linked Longitudinal Employer-Employee Data." U.S. Census Working Paper No. TP-2002-06.

Ackerberg, Daniel, C. Lanier Benkard, Steven Berry, and Ariel Pakes. 2007. "Econometric Tools for Analyzing Market Outcomes." , ed. J. J. Heckman and E. E. Leamer Vol. 6 of Handbook of Econometrics, Chapter 63. Elsevier.

Almeida, Paul, and Bruce Kogut. 1999. "Localization of knowledge and the mobility of engineers in regional networks." Management Science, 45(7): 905-917.

Balsvik, Ragnhild. 2011. "Is Labor Mobility a Channel for Spillovers from Multinationals? Evidence from Norwegian Manufacturing." Review of Economics and Statistics, 93(1): 285-297.

Cornelissen, Thomas. 2008. "The Stata command felsdvreg to fit a linear model with two high-dimensional fixed effects." The Stata Journal, 8(2): 170-189.

Dasgupta, Kunal. 2012. "Learning and knowledge diffusion in a global economy." Journal of International Economics, 87(2): 323-336.

Fosfuri, Andrea, Massimo Motta, and Thomas Ronde. 2001. "Foreign direct investment and spillovers through workers' mobility." Journal of International Economics, 53: 205-222.

Glass, Amy J., and Kamal Saggi. 2002. "Multinational firms and technology transfer." Scandinavian Journal of Economics, 104: 495-513. 
Gorg, Holger, and Eric Strobl. 2005. "Spillovers from Foreign Firms through Worker Mobility: An Empirical Investigation." Scandinavian Journal of Economics, 107(4): 693709.

Jorda, Oscar. 2005. "Estimation and Inference of Impulse Responses by Local Projections." American Economic Review, 95(1): 161-182.

Markusen, James R., and Natalia Trofimenko. 2009. "Teaching locals new tricks: Foreign experts as a channel of knowledge transfers." Journal of Development Economics, 88(1): 120-131.

Markussen, James R. 2001. "Contracts, intellectual property rights, and multinational investment in developing countries." Journal of International Economics, 53: 189-204.

Oettl, Alexander, and Ajay Agrawal. 2008. "International Labor Mobility and Knowledge Flow Externalities." Journal of International Business Studies, 39: 1242-1260.

Olley, Steven G., and Ariel Pakes. 1996. "The Dynamics of Productivity in the Telecommunications Equipment Industry." Econometrica, 64(6): 1263-97.

Pakes, Ariel. 1994. "The Estimation of Dynamic Structural Models: Problems and Prospects." , ed. Jean-Jacques Laffont and Christopher Sims Advances in Econometrics: Proceedings of the 6th World Congress, Chapter 5. Econometric Society.

Parrotta, Pierpaolo, and Dario Pozzoli. 2012. "The effect of learning by hiring on productivity." RAND Journal of Economics, 43(1): 167-185.

Pesola, Hanna. 2011. "Labour Mobility and Returns to Experience in Foreign Firms." Scandinavian Journal of Economics, 113(3): 637-664.

Poole, Jenifer Pamela. 2013. "Knowledge Transfers from Multinational to Domestic Firms: Evidence from Worker Mobility." Review of Economics and Statistics, 95(2): 393406. 
Singh, Jasjit, and Ajay Agrawal. 2011. "Recruiting for Ideas: How Firms Exploit the Prior Inventions of New Hires." Management Science, 57(1): 129-150.

Smith, Jennifer C. 1996. "Wage interactions: comparisons or fall-back options." Economic Journal, 106: 495-506.

Song, Jaeyong, Paul Almeida, and Geraldine Wu. 2003. "Learning-by-Hiring: When Is Mobility More Likely to Facilitate Inter-Firm Knowledge Transfer." Management Science, 29(4): 351-365.

Stoyanov, Andrey, and Nikolay Zubanov. 2012. "Productivity Spillovers Across Firms through Worker Mobility." American Economic Journal: Applied Economics, 4(2): 168198.

Teulings, Coen, and Nikolay Zubanov. forthcoming. "Is Economic Recovery a Myth? Robust Estimation of Impulse Responses." Journal of Applied Econometrics.

Wooldridge, Jeffrey M. 2009. "On estimating firm-level production functions using proxy variables to control for unobservables." Economics Letters, 104(3): 112-114. 
Figure 1. Wage profile of spillover potentials relative to other workers
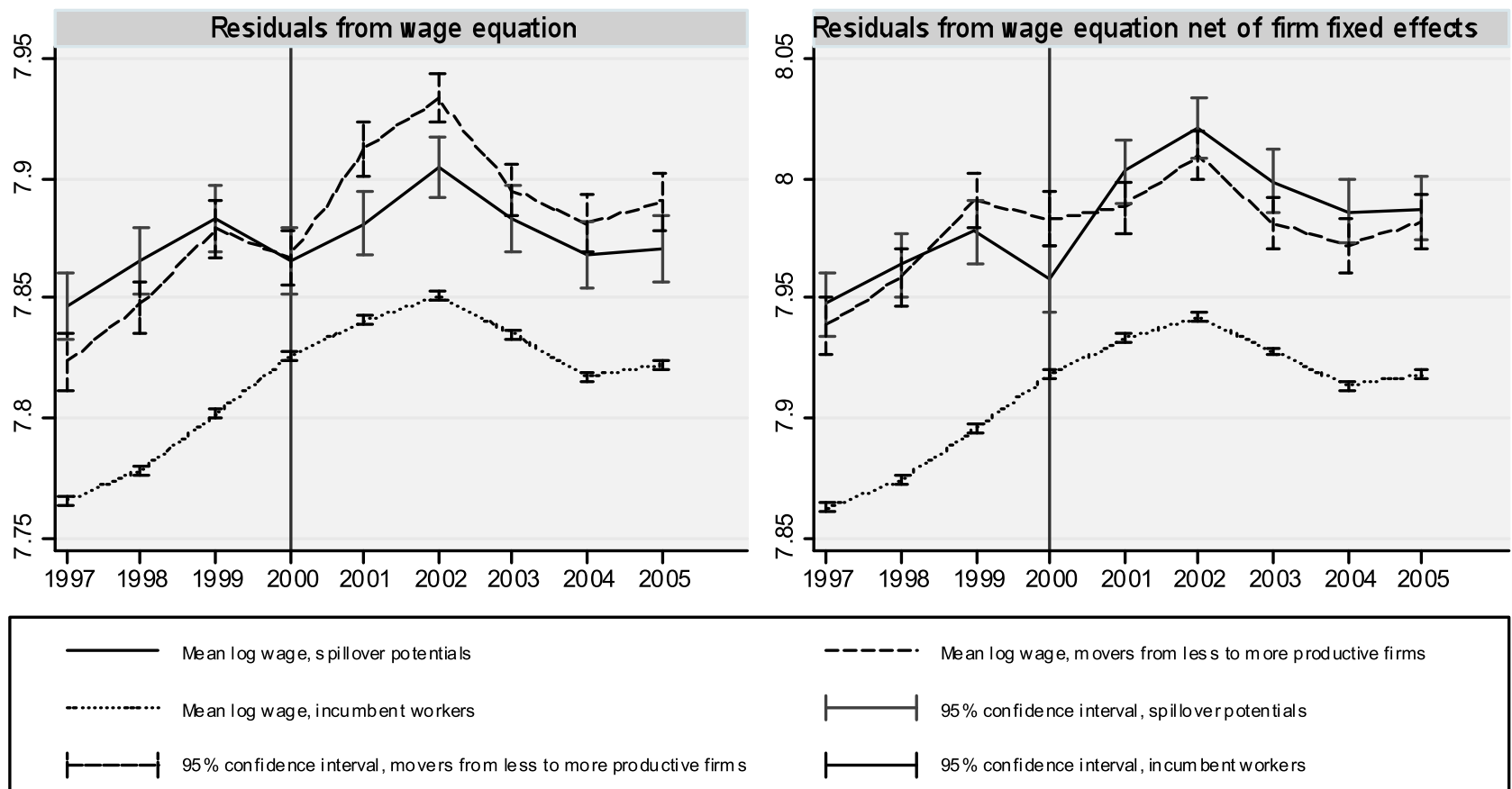

- Me an log wage, movers from les s to m ore prod uctive firms

$\longmapsto 95 \%$ confidence interval, spillover potentials

$\longmapsto 95 \%$ confidence interval, incum bent workers

Note: On this figure all job changes are as of 2000 . 
Figure 2. Wage profile of spillover potentials for the first and fourth quartiles of the gap
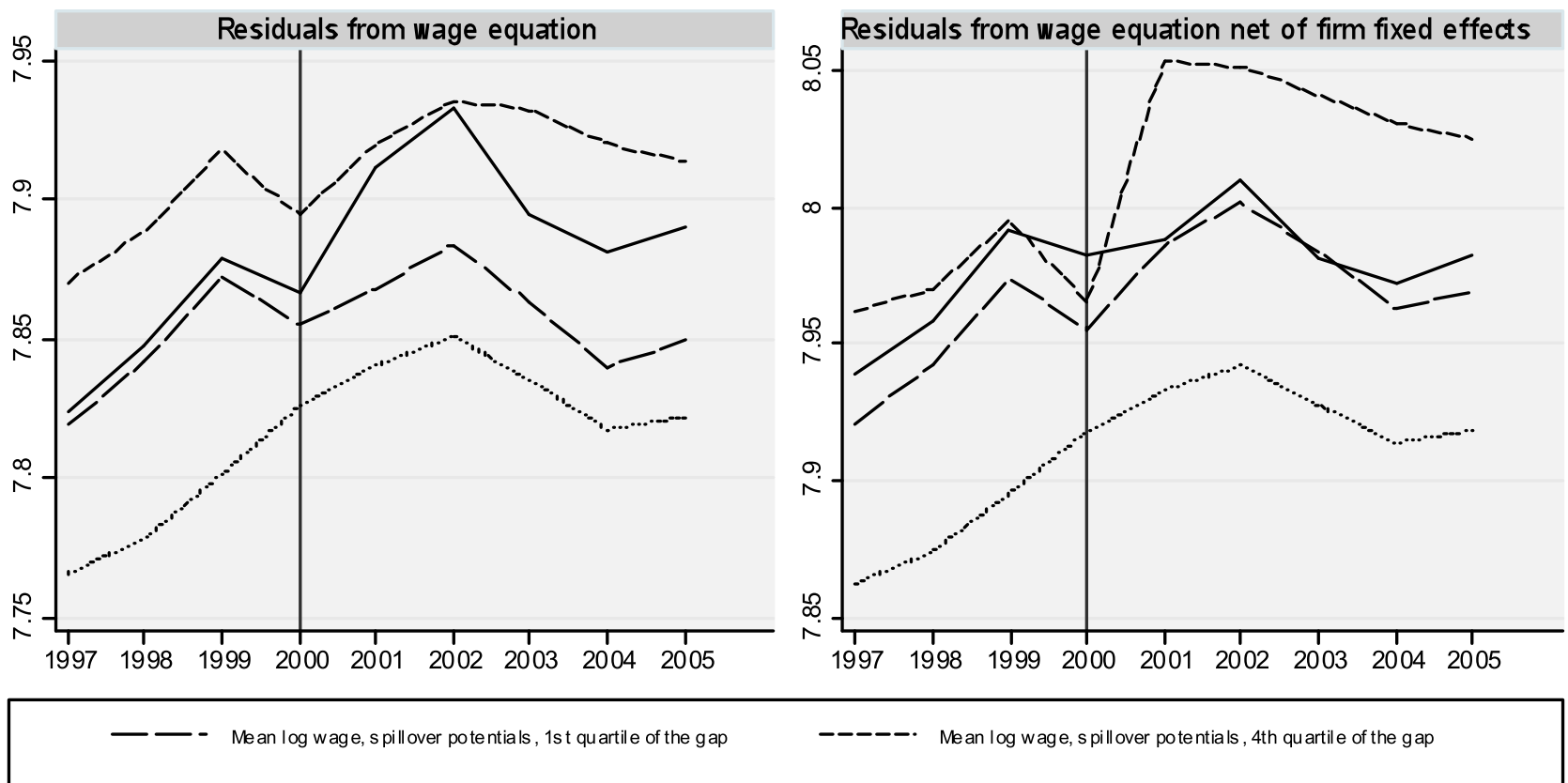

----D. Mean log wage, s pillover potentials, 4th quartile of the gap

Mean log wage, movers from les s to more productive firms

Mean log wage, incumbent workers

Note: On this figure all job changes are as of 2000 . 
Table 1. Mean values for selected firms' and workers' characteristics

\begin{tabular}{|c|c|c|c|c|c|}
\hline & \multicolumn{2}{|c|}{ Workers } & \multicolumn{2}{|c|}{ Firms } & \multirow[b]{2}{*}{$\begin{array}{l}\text { Representative } \\
\text { firm }\end{array}$} \\
\hline & All workers & $\begin{array}{l}\text { Spillover } \\
\text { potentials }\end{array}$ & All firms & $\begin{array}{l}\text { Firms that } \\
\text { hire } \\
\text { spillover } \\
\text { potentials }\end{array}$ & \\
\hline Log wage & 12.544 & 12.457 & 12.093 & 12.168 & 12.352 \\
\hline Log human capital & 12.615 & 12.569 & 12.462 & 12.483 & 12.540 \\
\hline High school (share) & 0.341 & 0.312 & 0.385 & 0.395 & 0.378 \\
\hline College (share) & 0.602 & 0.633 & 0.578 & 0.567 & 0.562 \\
\hline University (share) & 0.057 & 0.056 & 0.036 & 0.038 & 0.060 \\
\hline Low skilled (share) & 0.154 & 0.125 & 0.374 & 0.252 & 0.184 \\
\hline Mid skilled (share) & 0.606 & 0.640 & 0.502 & 0.593 & 0.595 \\
\hline High skilled (share) & 0.133 & 0.128 & 0.064 & 0.084 & 0.124 \\
\hline Managers (share) & 0.107 & 0.108 & 0.060 & 0.072 & 0.097 \\
\hline Age & 41.60 & 37.43 & 40.25 & 38.51 & 39.94 \\
\hline Log Experience & 9.669 & 9.433 & 9.293 & 9.281 & 9.450 \\
\hline Male (share) & 0.701 & 0.755 & 0.700 & 0.719 & 0.693 \\
\hline Separation rate & 0.099 & 0.125 & 0.132 & 0.159 & 0.095 \\
\hline Hiring rate & 0.092 & 0.194 & 0.081 & 0.156 & 0.091 \\
\hline Log employment & 5.348 & 4.57 & 2.348 & 3.359 & 5.314 \\
\hline Log output & 12.443 & 11.539 & 9.137 & 10.191 & 12.381 \\
\hline Log capital stock & 10.833 & 9.920 & 7.439 & 8.520 & 10.774 \\
\hline Log material input & 11.506 & 10.697 & 8.136 & 9.268 & 11.451 \\
\hline Number of obs. & $1,816,843$ & 38,838 & 72,586 & 24,337 & 72,586 \\
\hline
\end{tabular}

Notes: Summary statistics is calculated for the time period 1995-2007. Representative firm is defined as the average manufacturing industry output weighted by firms' share in total output. 
Table 2. Summary statistics for productivity gap and share of spillover potentials

\begin{tabular}{|c|c|c|c|c|c|c|c|c|c|}
\hline & \multicolumn{9}{|c|}{ FIRMS } \\
\hline & \multicolumn{3}{|c|}{ OLS } & \multicolumn{3}{|c|}{ OP } & \multicolumn{3}{|c|}{ WOP } \\
\hline & $\begin{array}{c}\text { Simple } \\
\text { mean }\end{array}$ & $\begin{array}{l}\text { Weighted } \\
\text { mean }\end{array}$ & $\begin{array}{l}\text { Std. } \\
\text { dev. }\end{array}$ & $\begin{array}{c}\text { Simple } \\
\text { mean }\end{array}$ & $\begin{array}{l}\text { Weighted } \\
\text { mean }\end{array}$ & $\begin{array}{l}\text { Std. } \\
\text { dev. }\end{array}$ & $\begin{array}{c}\text { Simple } \\
\text { mean }\end{array}$ & $\begin{array}{l}\text { Weighted } \\
\text { mean }\end{array}$ & $\begin{array}{l}\text { Std. } \\
\text { dev. }\end{array}$ \\
\hline Gap & 0.3007 & 0.2531 & 0.3102 & 0.4209 & 0.2927 & 0.3822 & 0.3701 & 0.2725 & 0.3692 \\
\hline Share of SPs & 0.0280 & 0.0213 & 0.0607 & 0.0276 & 0.0183 & 0.0580 & 0.0268 & 0.0188 & 0.0579 \\
\hline \multirow[t]{4}{*}{ Gap times share SPs } & 0.0077 & 0.0062 & 0.0193 & 0.0116 & 0.0070 & 0.0290 & 0.0097 & 0.0064 & 0.0257 \\
\hline & \multicolumn{9}{|c|}{ WORKERS } \\
\hline & \multicolumn{3}{|c|}{ OLS } & \multicolumn{3}{|c|}{ OP } & \multicolumn{3}{|c|}{ WOP } \\
\hline & $\begin{array}{c}\text { Simple } \\
\text { mean }\end{array}$ & $\begin{array}{l}\text { Weighted } \\
\text { mean }\end{array}$ & $\begin{array}{l}\text { Std. } \\
\text { dev. }\end{array}$ & $\begin{array}{l}\text { Simple } \\
\text { mean }\end{array}$ & $\begin{array}{l}\text { Weighted } \\
\text { mean }\end{array}$ & $\begin{array}{l}\text { Std. } \\
\text { dev. }\end{array}$ & $\begin{array}{c}\text { Simple } \\
\text { mean }\end{array}$ & $\begin{array}{l}\text { Weighted } \\
\text { mean }\end{array}$ & $\begin{array}{l}\text { Std. } \\
\text { dev. }\end{array}$ \\
\hline Gap & 0.2257 & & 0.2357 & 0.2811 & & 0.2470 & 0.2456 & & 0.2331 \\
\hline Share of SPs & 0.0261 & & & 0.0209 & & & 0.0214 & & \\
\hline Gap times share SPs & 0.0059 & & 0.0524 & 0.0059 & & 0.0538 & 0.0053 & & 0.0492 \\
\hline
\end{tabular}


Table 4. Estimation results for the individual wage equation (13)

\begin{tabular}{|c|c|c|c|c|c|c|}
\hline & (1) & (2) & (3) & (4) & (5) & (6) \\
\hline & OLS & OLS & OP & OP & WOP & WOP \\
\hline \multirow{2}{*}{$\operatorname{Gap}(\gamma)$} & $0.058 * *$ & $0.033^{* *}$ & $0.063 * *$ & $0.027 * *$ & $0.065 * *$ & $0.032 * *$ \\
\hline & $(0.009)$ & $(0.007)$ & $(0.016)$ & $(0.008)$ & $(0.014)$ & $(0.008)$ \\
\hline \multirow{4}{*}{ Gap negative $\left(\gamma^{-}\right)$} & 0.021 & 0.010 & 0.015 & 0.009 & 0.016 & 0.008 \\
\hline & $(0.013)$ & $(0.007)$ & $(0.010)$ & $(0.011)$ & $(0.012)$ & $(0.012)$ \\
\hline & \multicolumn{6}{|c|}{ Wage premium relative to labor productivity advantage } \\
\hline & 0.079 & 0.050 & 0.124 & 0.077 & 0.104 & 0.056 \\
\hline $\begin{array}{l}\text { Controls for new and } \\
\text { incumbent worker } \\
\text { characteristics }\end{array}$ & NO & YES & NO & YES & NO & YES \\
\hline R2 & 0.281 & 0.518 & 0.273 & 0.505 & 0.275 & 0.506 \\
\hline $\mathrm{N}$ & $2,823,582$ & $2,373,172$ & $2,047,870$ & $1,813,234$ & $2,051,805$ & $1,816,782$ \\
\hline \multicolumn{7}{|c|}{$\begin{array}{l}\text { Notes: The dependent variable is the log of worker's wage. }{ }^{*} \text { significant at } 5 \%,{ }^{*} \text { significant at } 1 \% \text {. The TFP is } \\
\text { estimated with OLS in columns (1)-(2), OP in columns (3)-(4), and WOP in columns (5)-(6). Standard errors in } \\
\text { parentheses are clustered by firm. The time period covered is 1995-2007. All specifications include firm-year fixed } \\
\text { effects, dummy variables for job changers coming from more and less productive firms, Abowd, Kramarz and } \\
\text { Margolis (1999) measure of human capital calculated separately for the workers hired from more and less } \\
\text { productive firms, as well as for the incumbent workers, and dummy variables for the number of job transitions } \\
\text { during the sample period. Worker observable characteristics include gender, age, experience, education, and } \\
\text { occupation. }\end{array}$} \\
\hline
\end{tabular}


Table 5. Estimation results for the firm-average wage equation (13)

\begin{tabular}{|c|c|c|c|c|c|c|c|c|c|}
\hline & (1) & $(2)$ & (3) & (4) & (5) & (6) & (7) & (8) & (9) \\
\hline & OLS & OLS & OLS & OP & OP & OP & WOP & WOP & WOP \\
\hline \multirow{2}{*}{ Gap positive $(\Gamma)$} & $0.248 * *$ & $0.126^{*}$ & $0.121^{*}$ & $0.314^{* *}$ & $0.233 * *$ & $0.154^{* *}$ & $0.316 * *$ & $0.193 * *$ & $0.146 * *$ \\
\hline & $(0.082)$ & $(0.058)$ & $(0.055)$ & $(0.096)$ & $(0.071)$ & $(0.059)$ & $(0.104)$ & $(0.054)$ & $(0.052)$ \\
\hline \multirow{2}{*}{ Gap negative $\left(\Gamma^{-}\right)$} & 0.133 & 0.061 & 0.051 & 0.055 & $0.094^{*}$ & 0.016 & 0.092 & $0.122 *$ & 0.030 \\
\hline & $(0.082)$ & $(0.058)$ & $(0.054)$ & $(0.048)$ & $(0.044)$ & $(0.053)$ & $(0.075)$ & $(0.058)$ & $(0.031)$ \\
\hline $\begin{array}{l}\text { Controls for firm } \\
\text { characteristics }\end{array}$ & NO & YES & YES & NO & YES & YES & NO & YES & YES \\
\hline $\begin{array}{l}\text { Controls for new and } \\
\text { incumbent worker } \\
\text { characteristics }\end{array}$ & NO & NO & YES & NO & NO & YES & NO & NO & YES \\
\hline R2 & 0.283 & 0.313 & 0.354 & 0.394 & 0.401 & 0.566 & 0.375 & 0.397 & 0.561 \\
\hline $\mathrm{N}$ & 105,427 & 105,427 & 105,427 & 71,433 & 71,433 & 71,433 & 72,611 & 72,611 & 72,611 \\
\hline & 0.0010 & 0.0008 \\
\hline \multicolumn{10}{|l|}{ Average effect on wage } \\
\hline Effect on average wage & 0.0018 & 0.0011 & 0.0009 & 0.0022 & 0.0017 & 0.0011 & 0.0020 & 0.0014 & 0.0009 \\
\hline \multicolumn{10}{|c|}{$\begin{array}{l}\text { Notes: The dependent variable is the firm-year average of log wage. }{ }^{*} \text { significant at } 5 \%,{ }^{*} \text { significant at } 1 \% \text {. The TFP is estimated } \\
\text { with OLS in columns (1)-(3), OP in columns (4)-(6), and WOP in columns (7)-(9). Standard errors in parentheses are clustered by } \\
\text { firms. Time period covered is } 1995-2007 \text {. All specifications include Abowd, Kramarz and Margolis (1999) measure of human } \\
\text { capital calculated separately for the workers hired from more and less productive firms, as well as for the incumbent workers, } \\
\text { firm fixed effects, industry-year fixed effects, estimated productivity shocks in periods (t-1) to (t-2), dummy variables for job } \\
\text { changers coming from more and less productive firms, and dummy variables for the number of job transitions during the sample } \\
\text { period. Firm characteristics include separation rate, shares of new workers from less and more productive firms in total } \\
\text { employment, log of labor and capital in the hiring firm. Worker observable characteristics include gender, age, experience, } \\
\text { education, and occupation. }\end{array}$} \\
\hline
\end{tabular}


Table 6. Distribution of gains from spillovers between workers and firms

\begin{tabular}{|c|c|c|c|c|c|c|}
\hline & (1) & (2) & (3) & (4) & (5) & (6) \\
\hline & \multicolumn{3}{|c|}{$\varphi=0.223$} & \multicolumn{3}{|c|}{$\varphi=0.333$} \\
\hline & OLS & OP & WOP & OLS & OP & WOP \\
\hline Output gain & $0.155 \%$ & $0.097 \%$ & $0.109 \%$ & $0.155 \%$ & $0.097 \%$ & $0.109 \%$ \\
\hline $\begin{array}{l}\text { Share of output gain } \\
\text { retained by the firm }\end{array}$ & $87.45 \%$ & $75.99 \%$ & $81.22 \%$ & $81.25 \%$ & $64.15 \%$ & $71.96 \%$ \\
\hline $\begin{array}{l}\text { Share of output gain } \\
\text { going to SPs }\end{array}$ & $2.28 \%$ & $3.18 \%$ & $3.01 \%$ & $3.41 \%$ & $4.75 \%$ & $4.50 \%$ \\
\hline $\begin{array}{l}\text { Share of output gain } \\
\text { going to non-SPs }\end{array}$ & $10.27 \%$ & $20.82 \%$ & $15.77 \%$ & $15.34 \%$ & $31.10 \%$ & $23.54 \%$ \\
\hline \multicolumn{7}{|c|}{$\begin{array}{l}\text { Notes: The productivity gap is estimated with OLS in columns (1) and (4), OP in columns (2) and (5), } \\
\text { and WOP in columns ( } 3 \text { ) and (6). The shares of gains going to firms, SPs and other workers are } \\
\text { calculated using equation (16). In Columns (1)-(3) the share of labor in total output is assigned to } \\
0.223 \text {, which is the sample average share of wages in total output. In Columns (4)-(6) the same share } \\
\text { is assigned to } 0.333 \text {, which is the labor input elasticity in the most complete production function } \\
\text { specification estimated with WOP. }\end{array}$} \\
\hline
\end{tabular}


Table 7. Output and wage gains from spillovers through worker mobility within and between industry groups

\begin{tabular}{|c|c|c|c|c|c|c|c|c|c|}
\hline & (1) & (2) & (3) & (4) & (5) & (6) & (7) & (8) & (9) \\
\hline & \multicolumn{3}{|c|}{ Individual wage equation } & \multicolumn{3}{|c|}{ Prod. function equation } & \multicolumn{3}{|c|}{ Firm wage equation } \\
\hline & OLS & OP & WOP & OLS & OP & WOP & OLS & OP & WOP \\
\hline \multirow{2}{*}{$\begin{array}{l}\text { Gap, same } \\
\text { industry }\end{array}$} & $0.025 * *$ & $0.040 * *$ & $0.040 * *$ & $0.470 * *$ & $0.294^{* *}$ & $0.347^{* *}$ & $0.123^{*}$ & $0.192 * *$ & $0.213^{* *}$ \\
\hline & (0.009) & $(0.012)$ & $(0.012)$ & $(0.101)$ & $(0.106)$ & $(0.127)$ & $(0.061)$ & $(0.066)$ & $(0.073)$ \\
\hline \multirow{2}{*}{ Gap, diff. industry } & $0.035 * *$ & $0.044 * *$ & $0.044 * *$ & 0.104 & 0.095 & 0.072 & 0.069 & $0.142 * *$ & $0.133^{* *}$ \\
\hline & $(0.009)$ & $(0.010)$ & $(0.011)$ & $(0.070)$ & $(0.056)$ & $(0.060)$ & $(0.062)$ & $(0.052)$ & $(0.051)$ \\
\hline \multirow{2}{*}{$\begin{array}{l}\text { Gap negative, } \\
\text { same industry }\end{array}$} & 0.001 & 0.000 & 0.002 & $0.218^{*}$ & 0.114 & 0.123 & 0.055 & 0.061 & 0.093 \\
\hline & (0.010) & $(0.013)$ & $(0.012)$ & $(0.106)$ & $(0.090)$ & $(0.126)$ & $(0.040)$ & $(0.067)$ & $(0.073)$ \\
\hline \multirow{2}{*}{$\begin{array}{l}\text { Gap negative, diff. } \\
\text { industry }\end{array}$} & -0.012 & -0.013 & -0.009 & -0.098 & -0.072 & -0.054 & 0.017 & -0.067 & -0.009 \\
\hline & $(0.008)$ & $(0.010)$ & $(0.009)$ & $(0.090)$ & $(0.084)$ & $(0.120)$ & $(0.143)$ & $(0.088)$ & $(0.063)$ \\
\hline $\mathrm{R} 2$ & 0.521 & 0.506 & 0.507 & 0.980 & 0.981 & 0.975 & 0.348 & 0.316 & 0.311 \\
\hline $\mathrm{N}$ & $2,377,525$ & $1,815,753$ & $1,819,330$ & 105,437 & 71,456 & 72,632 & 105,380 & 71,412 & 72,586 \\
\hline \multicolumn{10}{|c|}{$\begin{array}{l}\text { Notes: The dependent variable is the log of individual worker's wage in columns (1)-(3), firm output in columns (4)-(6), and the } \\
\text { firm-year fixed effect estimated from individual wage equation (12) in columns (7)-(9). TFP and productivity gaps were } \\
\text { constructed from the Cobb-Douglas production function estimated by one-step GMM estimator by Wooldridge (2009). * } \\
\text { significant at } 5 \% \text {, ** significant at } 1 \% \text {. Time period covered is } 1995-2007 \text {. Specifications (1)-(3) include firm-year fixed effects, } \\
\text { dummy variables for job changers coming from more and less productive firms, human capital measure calculated separately for } \\
\text { the workers hired from more and less productive firms, as well as for the incumbent workers, dummy variables for the number of } \\
\text { job transitions during the sample period, gender, age, experience, education, and occupation. Specifications (4)-(9) include } \\
\text { industry-year fixed effects, estimated TFP shocks in years (t-1) to (t-2), separation rates and shares of new workers from less and } \\
\text { more productive firms in total employment, and firm-year average of employees characteristics such as gender, age, experience, } \\
\text { education, occupation, human capital measures of the workers hired from more and less productive firms and of the incumbent } \\
\text { workers. Specifications (7)-(9) also include firm fixed effects. }\end{array}$} \\
\hline
\end{tabular}


Table 8. Output and wage gains by worker skill level

(1) (2) (3) (4)

\begin{tabular}{lcccc} 
Spillover potentials by skill group: & Low skill & Mid skill & High skill & Manager \\
\hline Gap's coefficient in production function $(\theta)$ & 0.158 & 0.146 & 0.377 & 0.550 \\
Gap's coefficient in individual wage equation $(\gamma)$ & 0.022 & 0.034 & 0.034 & 0.065 \\
Gap's coefficient in firm wage equation $(\Gamma)$ & 0.131 & 0.166 & 0.411 & 0.584 \\
Output gain (\%) & 0.016 & 0.053 & 0.034 & 0.045 \\
LPA (\%) & 6.93 & 10.71 & 21.14 & 29.22 \\
Average gain per worker, overall (\%) & 0.010 & 0.063 & 0.031 & 0.043 \\
Average wage gain per worker, SPs (\%) & 0.570 & 0.848 & 0.920 & 1,930 \\
Average wage gain per worker, non-SPs (\%) & 0.009 & 0.052 & 0.029 & 0.039 \\
Share of gain retained by the firms (\%) & 79.16 & 60.66 & 69.19 & 68.33 \\
Share of gain retained by SPs (\%) & 2.98 & 6.71 & 2.36 & 3.21 \\
Share of gain retained by other workers (\%) & 17.85 & 32.63 & 28.45 & 28.46 \\
Share in labor force (\%) & 0.28 & 1.37 & 0.27 & 0.23 \\
\hline
\end{tabular}

Notes: TFP measure used to define spillover potentials was constructed from the Cobb-Douglas production function estimated with WOP. 
Table 9. Productivity and wage gains from worker mobility in the years after hiring.

\begin{tabular}{lccccc}
\hline & $(1)$ & $(2)$ & $(3)$ & $(4)$ & $\begin{array}{c}(5) \\
\text { Year } 5\end{array}$ \\
\hline Gap's coefficient in production function $(\theta)$ & 0.201 & 0.214 & 0.265 & 0.238 & 0.164 \\
Gap's coefficient in individual wage equation $(\gamma)$ & 0.032 & 0.042 & 0.037 & 0.038 & 0.027 \\
Gap's coefficient in firm wage equation $(\Gamma)$ & 0.182 & 0.226 & 0.279 & 0.174 & 0.120 \\
Output gain (\%) & 0.129 & 0.137 & 0.170 & 0.152 & 0.105 \\
LPA (\%) & 16.48 & 17.54 & 21.73 & 19.51 & 13.45 \\
Average gain per worker, overall (\%) & 0.096 & 0.120 & 0.148 & 0.092 & 0.064 \\
Average wage gain per worker, SPs (\%) & 0.865 & 1,129 & 1,037 & 1,005 & 0.712 \\
Average wage gain per worker, non-SPs (\%) & 0.080 & 0.098 & 0.128 & 0.072 & 0.049 \\
Share of gain retained by the firms (\%) & 80.02 & 77.45 & 77.50 & 83.22 & 83.21 \\
Share of gain retained by SPs (\%) & 3.84 & 4.55 & 3.38 & 3.91 & 4.02 \\
Share of gain retained by other workers (\%) & 16.14 & 18.00 & 19.12 & 12.86 & 12.77 \\
\hline Notes: TFP measure used to define spillover potentials & was constructed from the Cobb-Douglas production function \\
estimated with WOP. & & & & &
\end{tabular}

